NBER WORKING PAPER SERIES

\title{
TECHNOLOGY ADOPTION UNDER UNCERTAINTY: TAKE-UP AND SUBSEQUENT INVESTMENT IN ZAMBIA
}

\author{
B. Kelsey Jack \\ Paulina Oliva \\ Christopher Severen \\ Elizabeth Walker \\ Samuel Bell \\ Working Paper 21414 \\ http://www.nber.org/papers/w21414
NATIONAL BUREAU OF ECONOMIC RESEARCH
1050 Massachusetts Avenue
Cambridge, MA 02138
July 2015

Helpful comments were received from Jim Berry, Chris Costello, Andrew Foster, Alex Pfaff, Andrew Plantinga, Stephen Ryan, Kenneth Train, Mushfiq Mobarak, Ryan Kellogg, Tavneet Suri and audiences at numerous seminars and conferences. The authors thank the IGC, CDKN and Musika for financial support, and the Center for Scientific Computing from the CNSI and MRL at UC Santa Barbara (NSF MRSEC DMR-1121053 and NSF CNS-0960316) for use of its computing cluster. Field work was facilitated by Innovations for Poverty Action, with specific thanks to Jonathan Green, Farinoz Daneshpay, Mwela Namonje and Monica Banda. The project was made possible by the collaboration and support of Shared Value Africa and Dunavant Cotton, Ltd. The views expressed herein are those of the authors and do not necessarily reflect the views of the National Bureau of Economic Research.

NBER working papers are circulated for discussion and comment purposes. They have not been peerreviewed or been subject to the review by the NBER Board of Directors that accompanies official NBER publications.

(C) 2015 by B. Kelsey Jack, Paulina Oliva, Christopher Severen, Elizabeth Walker, and Samuel Bell. All rights reserved. Short sections of text, not to exceed two paragraphs, may be quoted without explicit permission provided that full credit, including $(\mathbb{C}$ notice, is given to the source. 
Technology Adoption Under Uncertainty: Take-Up and Subsequent Investment in Zambia B. Kelsey Jack, Paulina Oliva, Christopher Severen, Elizabeth Walker, and Samuel Bell NBER Working Paper No. 21414

July 2015

JEL No. D81,O13,Q12

\begin{abstract}
$\underline{\text { ABSTRACT }}$
Many technology adoption decisions are made under uncertainty about the costs or benefits of subsequent investments in the technology after the initial take-up. As new information is realized, agents may prefer to abandon a technology that appeared profitable at the time of take-up. Low rates of follow-through (engagement in subsequent investments) are particularly problematic when subsidies are used to increase adoption, in part because they may attract users with a lower value for the technology. We use a field experiment with two stages of randomization to generate exogenous variation in the payoffs associated with taking up and following through with a new technology: a tree species that provides private fertilizer benefits to adopting farmers. Our empirical results show high rates of abandoning the technology, even after paying a positive price to take it up. The experimental variation offers a novel source of identification for a structural model of intertemporal decision making under uncertainty. Estimation results indicate that the farmers experience idiosyncratic shocks to net payoffs after take-up, which increase take-up but lower average per farmer tree survival. We simulate counterfactual outcomes under different levels of uncertainty and observe that subsidizing take-up of the technology affects the composition of adopters only when the level of uncertainty is relatively low. Thus, uncertainty provides an additional explanation for why many subsidized technologies may not be utilized even when take-up is high.
\end{abstract}

B. Kelsey Jack

Department of Economics

Tufts University

314 Braker Hall

Medford, MA 02155

and NBER

kelsey.jack@tufts.edu

Paulina Oliva

Department of Economics

2127 North Hall

University of California

Santa Barbara, CA 93106

and NBER

oliva@econ.ucsb.edu

Christopher Severen

University of California at Santa Barbara

Department of Economics

cseveren@umail.ucsb.edu

An online appendix is available at:

http://www.nber.org/data-appendix/w21414
Elizabeth Walker

NERA Economic Consulting

elizabeth_walker@hksphd.harvard.edu

Samuel Bell

Shared Value Africa

and Cornell University

sdb44@cornell.edu 


\section{Introduction}

Many technology adoption decisions consist of at least two parts, which occur at different points in time: an initial take-up decision and a subsequent investment or follow-through decision. While subsidies are often used to increase take-up, critics of subsidies for technology adoption, in development, health and environmental policy, worry that subsidizing the initial take-up decision may lower subsequent follow-through: Are agricultural technologies fully utilized if their take-up is subsidized? Are people as likely to take subsidized health treatments according to their directions? Will subsidies for home energy audits lower weatherization rates among those receiving audits?

Numerous studies have examined the reasons why follow-through might be affected by the initial cost of the technology, including screening or selection effects, learning, and psychological channels such as sunk cost effects or procrastination (Ashraf et al. 2010; Cohen and Dupas 2010; Mahajan and Tarozzi 2011; Ashraf et al. 2013; Dupas 2014; Beaman et al. 2014; Fischer et al. 2014; Carter et al. 2014; Cohen et al. 2015). With the exception of learning, little attention has been paid to the role of uncertainty in the initial take-up decision. ${ }^{1}$ Specifically, at the time of take-up, many of the benefits and costs associated with the follow-through decision may be unknown. New information arrives in the form of learning about the technology (Foster and Rosenzweig 1995; Conley and Udry 2010; Oster and Thornton 2012; Hanna et al. 2014) or in the form of transient shocks to the opportunity cost of follow-through. If the new information is bad news about the profitability of the technology, then adopters may prefer to abandon the technology as long as it is cheap to do so.

We study both technology take-up and follow-through decisions under uncertainty in the context of an agricultural technology in Zambia. The technology requires both a one-time take-up decision and a subsequent investment decision, which we refer to as the follow-through decision. We start by developing a simplified and general theoretical model that shows that uncertainty about the profitability of a technology lowers follow-through and undermines the degree to which a higher initial price of the technology screens out individuals who are unlikely to follow-through. Exploiting a field experiment on the adoption of trees in Zambia, we then provide reduced form evidence that uncertainty explains low follow-through. In the context of tree adoption, uncertainty about the opportunity cost of adoption could take many forms, including illness of a household member, shocks (either positive or negative) to other crops, such as pests or weather, that result in a reallocation of labor resources, shocks to the trees themselves, etc. For our empirical application, we refer to uncertainty as non-zero variance in all shocks to the opportunity cost of following through, including (but not restricting to) the ones just listed. Our experimental data identifies a structural model, which (a) shows that most of our reduced form results can be replicated by a data generating

\footnotetext{
${ }^{1}$ A substantial literature investigates how technology adoption and investment is affected by risk or uncertainty but does not explicitly investigate the relationship between the initial take-up decision and the subsequent use of the technology, or the effect of subsidies for take-up. Related empirical studies of adoption under uncertainty are found in both environmental economics (e.g., Stavins and Jaffe 1990; Hassett and Metcalf 1993; Schatzki 2003; Ansar and Sparks 2009) and in development economics (e.g., Cole et al. 2013; Karlan et al. 2014; Cai et al. 2015).
} 
process that is fully consistent with the presence of uncertainty, and (b) allows us to perform counterfactual simulations of take-up and follow-through outcomes at different levels of uncertainty. The simulations highlight the impact of uncertainty on farmer decisions and show that only at low levels of uncertainty do higher prices positively screen for follow-through.

To develop intuition, we begin with a stylized model of intertemporal adoption under uncertainty in the presence of subsidies, where adoption consists of a take-up and a follow-through decision, both of which are binary. ${ }^{2}$ The net costs of adoption include any direct costs or opportunity costs, net of benefits, associated with following-through with the technology. In our setting, the only cost associated with take-up is assumed to be the price of the technology, which may be subsidized. The model allows for some share of these net costs of adoption to be observed at the time the take-up decision is made, and the remaining share to be observed at the time of the follow-through decision. The net costs that are unobserved at the time of take-up represent the uncertainty that the adopter faces, and the model does not specify whether new information arrives as a transient shock or as learning. ${ }^{3}$ The theoretical model generates clear predictions about the relationship between uncertainty and adoption outcomes. First, as uncertainty increases, take-up becomes more attractive as long as the follow-through decision can be postponed until after additional information is revealed. The expected profit of take-up therefore includes an option value associated with the decision to abandon the technology if the new information makes follow-through unprofitable. Second, as the share of information that is unobserved at the time of take-up increases, the decision to take-up becomes less predictive of follow-through and high take-up rates may be accompanied by low follow-through. Third, uncertainty undermines the screening effect of the take-up price: if adopters know little about their net cost of follow-through when they take-up, then a higher take-up price will not be effective at screening out those who realize a high cost at follow-through. It is worth clarifying that shocks to net costs could increase or decrease the relative profitability of the technology; the upside of the shock distribution generates an option value of taking-up whether or not the individual is insured against negative shocks. Thus, the results of our conceptual model apply to a broad set of contexts outside of the relatively uninsured and high-risk environment of agricultural decisions in the developing world.

Next, we generate empirical evidence for the model using a multi-period field experiment in rural Zambia. Farmers decide whether to take-up and care for a tree species that generates private soil fertility benefits over the long term, but carries short-run costs. In addition to the private soil

\footnotetext{
${ }^{2}$ Much of the existing research focuses on adoption decisions where follow-through, or usage, has an intensive margin. This is true for durable goods such as bed nets, light bulbs, or stoves (Ashraf et al. 2010; Cohen and Dupas 2010; Berry et al. 2012; Dupas 2014). We focus on binary decisions because it simplifies the model and intuition. However, it is important to note that in our our empirical application, we introduce an intensive margin to the follow-through decision (how many trees to cultivate) and thus can empirically explore the the effect of uncertainty on both the extensive and intensive margins.

${ }^{3}$ Both the theoretical and the empirical models are agnostic as to how the uncertainty is resolved. In Section 7 , we provide some suggestive evidence that shocks are relatively more important than learning in our setting. However, our modeling framework is general enough to support multiple types of uncertainty.
} 
fertility benefits, tree adoption generates sizable public benefits in the form of carbon sequestration and reduction of soil erosion. ${ }^{4}$ We observe whether the 1,314 farmers in the study choose to purchase a 50-tree seedling package at the start of the agricultural cycle. The follow-through decision consists of the number of seedlings that the farmer chooses to plant and care for (which we together refer to as tree cultivation) and occurs over the course of the subsequent year. We measure follow-through as tree survival after one year, and assume that farmers can guarantee tree survival for some level of costly effort. ${ }^{5}$ Farmers who take-up the technology are subject to numerous shocks to their opportunity cost of follow-through, such as family illness, pests, weather and price shocks. Thus, the adoption decision that we study is one characterized by uncertainty in some share of the net costs of follow-through at the time of take-up. Farmers can abandon the technology without penalty in states of the world where scarce resources, such as labor, are more profitably allocated to other productive activities. Just as with other technologies, the costless exit in the face of uncertainty generates an option value tied to the take-up decision. ${ }^{6}$ The higher the uncertainty, the higher the option value and the more attractive the take-up decision becomes. ${ }^{7}$

We introduce exogenous variation into this adoption decision at two different points in time. First, we randomize the subsidy offered for the seedling package, effectively introducing random variation in take-up costs. This creates variation in take-up rates that helps characterize the distribution of expected net costs from the program across farmers. Second, we generate exogenous variation in the benefits of follow-through by varying the size and availability of a randomized threshold performance reward: a payment that is conditioned on the survival of 35 trees one year after take-up. The tree cultivation choices farmers make in response to the reward help us characterize the distribution of follow-through costs after potential shocks have been realized. Under the assumption that shocks are independent across farmers, the difference in the variance of net costs between the two points in time can be attributed to uncertainty. ${ }^{8}$ Note that, rather than artificially varying the allocation of shocks across our study population, the reward creates exogenous varia-

\footnotetext{
${ }^{4}$ The present value of sequestration associated with half a hectare of surviving trees is around USD 353. As we discuss in Section 3.1, the back-of-the-envelope cost benefit analysis is negative from the individual perspective but positive from a social standpoint, offering a potential justification for subsidies. Farmers, on the other hand, are not likely to consider these public benefits in their take-up decision.

${ }^{5}$ The choice of minimum effort that guarantees survival is optimal under convexity of the survival risk function as a function of effort. Therefore, the only source of uncertainty in tree survival according to our baseline model is the endogenous choice of follow-through by farmers, which depends on uncertain costs of effort. This assumption is examined in greater detail in Appendix A.3.

${ }^{6}$ The option value is akin to the "quasi-option" value described by Arrow and Fischer (1974): the value of the information revealed by delaying investment, or - in our case - the delayed decision to abandon the project. In this sense, the contract in our study is a put option (Pindyck 1993). Like Stange (2012), we calculate the option value as the difference between a binding participation decision and one with free exit.

${ }^{7}$ This is true even in the presence of insurance, as the costless exit is still present in this case and thus the contract becomes a substitute for insurance. See Giné and Yang (2009) for an example of how an uninsured credit contract may be more attractive than an insured one in the presence of limited liability.

${ }^{8}$ The cross-farmer independence assumption rules out common shocks. In a model variant, discussed in Section 5 , we also relax the independence assumption by allowing for an unexpected common shock to all farmers.
} 
tion in the variance of possible outcomes faced by the farmers, and therefore in the distribution of shocks. By offering a positive payoff, the performance reward mitigates some of the downside risk much in the way that varying the terms of an insurance contract has a state-contingent effect on the distribution of outcomes. ${ }^{9}$ In addition, the random variation in the subsidy to take-up allows us to identify the distribution of mean expected returns to take-up across farmers. Together, the different sources of variation at two points in time identify a structural model of intertemporal decisions that can distinguish between static and dynamic explanations for the outcomes that we observe. This is among the first papers to introduce multiple dimensions to the randomization design to distinguish between adoption decisions and returns to investment (see Karlan and Zinman (2009) and extensions of their design by Ashraf et al. (2010); Cohen and Dupas (2010) and others), and the first to use this research design to explore time-varying returns to investment.

Under fewer assumptions than are needed for the structural model, the research design produces a number of stylized facts and reduced form results that are consistent with the predictions of our theoretical model in the presence of uncertainty. First, farmer choices are sensitive to economic incentives: they are more likely to purchase the seedlings under higher take-up subsidies and higher rewards, and they are more likely to cultivate 35 or more trees when they are offered higher rewards. This simple observation rules out that take-up and follow-through decisions are divorced from economic incentives. We also observe greater investment in activities likely to increase tree survival among farmers with higher rewards. Second, our conceptual model predicts that in the absence of uncertainty, farmers would only pay a positive price for the technology if they intended to follow-through with a strictly positive number of trees. Contrary to this, we find that around 35 percent of farmers who paid a positive price for take-up have no trees one year later. ${ }^{10}$ Third, our model predicts that under high levels of uncertainty, the relationship between take-up subsidies and follow-through is weak: individuals have little incentive to self-select based on the likelihood of follow-through, and a strong incentive to take-up if uncertainty is high. ${ }^{11}$ Consistent with this, we find no observable reduced form relationship between the take-up price and follow-through. ${ }^{12}$

\footnotetext{
${ }^{9} \mathrm{~A}$ similar approach is used by Einav et al. (2013); Bryan et al. (2014); Karlan et al. (2014), among others. In these studies, the variation in uncertainty generated by insurance contracts is used to study its effect on technology adoption and other outcomes.

${ }^{10}$ We rule out a number of alternative motives for taking-up and cultivating zero trees, such as side-selling and experimenter demand effects, using a combination of the study design and our empirical results. These are further described in Section 4.

${ }^{11}$ Liquidity constraints could also affect self-selection and follow-through. However, strong liquidity constraints would result in low take-up, and the take-up rates we observe are high across all levels of the take-up subsidy. Furthermore, farmers receive a show-up fee sufficient to cover take-up costs. Finally, we include an additional test for self-selection that does not depend on liquidity: variation in the timing of the reward announcement. We discuss these tests for liquidity constraints and other confounds, such as sunk cost effects, in Section 4.

${ }^{12}$ Other studies have documented a correlation between take-up and returns to agricultural technologies and investment decisions. For example, Beaman et al. (2014) show that farmers with relatively high returns to credit self-select into an agricultural loan. Suri (2011), on the other hand, shows a negative correlation between returns to fertilizer and adoption in Kenya. Her findings can be explained by choices based on relative rather than absolute returns to technologies. Most similar to our application and setting, Jack (2013) provides evidence that farmers self-select based
} 
Although these facts suggest that uncertainty plays a role in farmers' decisions, we turn to our structural model to study this phenomenon more generally. First, are there sources of static heterogeneity (i.e. without uncertainty), such as differences in the returns to trees across farmers, that can explain the absence of a screening effect of the take-up subsidy? Second, how large is the uncertainty implied by farmers' decisions compared to the cross-sectional variation in expected net costs of adoption? Third, what is the magnitude of the private benefit associated with adoption under uncertainty and what share comes from the option to abandon the technology after new information is revealed? And finally, how much would uncertainty have to be reduced to generate a meaningful correlation between take-up subsidies and follow-through?

First, we note that, in theory, static heterogeneity in private benefits can also explain an absence of, or even negative, screening effects of prices whenever the follow-through decision has an intensive margin. Specifically, there may be heterogeneity in both the level of the profit (for example, if there are fixed costs to adoption) and in the optimal usage rate (i.e. in the interior solution to the maximization problem); and these two types of heterogeneity may or may not be correlated. Only a positive correlation between the level of private profit and privately optimal usage rates would generate higher follow-through rates among those who participate at higher cost (i.e. a positive screening effect of prices). Zero or negative correlation between profit and optimal usage rates could result in a null or negative screening effect of prices. ${ }^{13}$ To investigate the role of static heterogeneity in delivering similarly low follow-through outcomes across all levels of subsidy, our structural model allows for heterogeneity in the privately optimal number of trees as well as in the net cost of follow-through, and allows these two known (to the farmer) components of private profit to be freely correlated. This is akin to correlated random coefficient (CRC) models, where returns to the technology are allowed to differ across potential adopters and therefore influence their decision to adopt (Heckman et al. 2010). Similar to Suri (2011), we allow returns to differ along two dimensions (in our case optimal number of trees and net cost of follow-through), which allows for more flexible selection patterns. The distribution of privately optimal number of trees and the mean and variance (across farmers) of expected net costs are separately identified from the variance of the shocks to net costs; hence our model can distinguish between static and dynamic explanations for the lack of screening effects of prices. Our structural estimation delivers both a positive variance

on future costs into a tree planting incentive contract in Malawi. The magnitude of the self-selection effect that she measures is smaller after one year than after two or three years of tree survival, which may suggest that we would observe some self-selection in subsequent years. Note that this is also consistent with a multiple-year extension of our conceptual framework, which would predict stronger selection over time as high mean cost farmers are more likely to face shocks to opportunity cost that lead to irreversible tree deaths.

${ }^{13}$ Note that in many cases the source of heterogeneity in individual adoption choices is left unspecified. However, some source of heterogeneity, either static or transient, is necessary for take-up and follow-through decisions to differ across experiment participants within each branch of treatment. Most of the literature implicitly assumes that there is a positive correlation between the level of the profits and the privately optimal usage rate, which is necessary for "positive selection" i.e. a screening effect from the price (e.g., Ashraf et al., 2010; Cohen and Dupas, 2010; Beaman et al., 2014). A notable exception is Suri (2011), who offers evidence of a negative correlation between optimal rates of usage and fixed costs of adoption in the case of fertilizer. 
for the shocks to net cost, which offers a dynamic explanation for low tree survival, as well as a positive correlation between the component of net costs that is always observable to the farmer and the privately optimal number of trees (or a negative correlation between the level of private profit and the privately optimal number of trees). Both of these sources of heterogeneity reduce the ability of take-up prices to screen adopters that are likely to have high rates of follow-through.

Second, despite finding a substantial level of static heterogeneity in net costs (the standard deviation in the known component of net costs is 1.5 as large as the standard deviation of shocks), the scale of the shocks to profit appear to be economically meaningful and have a substantial effect on outcomes. ${ }^{14}$ Specifically, among farmers whose expected number of trees is above the reward threshold at the time of take-up, around 15 percent do not reach the threshold because their ex post optimal number of trees is lower than their ex ante expected number, once new information is accounted for. This is in addition to the 36 percent of farmers who choose to take-up cultivate zero trees even when the take-up cost is high, as shown in the reduced form results. Third, we also recover, via simulation, the share of the private net costs that are associated with the option to abandon the technology should the new information make follow-through. This option value is a substantial share of the private benefits associated with take-up, and drives the increase in expected benefits - and therefore the increase in take-up - as uncertainty increases.

Finally, to shed light on the amount of uncertainty that can eliminate screening effects, we implement counterfactual simulations that vary the magnitude of the uncertainty at the time of takeup, modeled as an increase in the standard deviation of the unknown cost component. Consistent with our theoretical model, uncertainty increases take-up and lowers follow-through conditional on take-up. Only at low levels of uncertainty do we see that higher prices for take-up have a positive effect on follow-through, by screening out farmers with a low probability of follow-through. If uncertainty is high enough, then subsidies will have little effect on either selection or take-up since the option value is high enough to generate high take-up rates at all prices.

Methodologically, our econometric framework is an example of sequential identification of subjective and objective opportunity cost components in a dynamic discrete choice model (Heckman and Navarro 2007, 2005). As described in Heckman and Navarro (2007), we can account for selection into treatment (in our case, the take-up of the tree planting program, as well as non-corner solution tree survival outcomes) when identifying the distribution of the unobserved opportunity cost determinants. We do so by introducing two layers of random variation in economic incentives, one of which produces a probability of take-up equal to one for a sub-population and a second of which produces interior solution in tree cultivation outcomes with probability one in the limit. The use of experimental variation in treatments at two different points in time offers an alternative

\footnotetext{
${ }^{14}$ More specifically, the model estimates the new information that arrives between the take-up and the followthrough decisions, which we refer to as a shock. As noted above, our empirical application does now allow us to cleanly distinguish between learning and shocks. Time inconsistent preferences (see e.g., Mahajan and Tarozzi (2011)) are also consistent with our model, as discussed in Section 7.
} 
to a panel data structure (used for example, in Einav et al. 2013), since statistically independent samples are exposed to each of the different treatment combinations. To our knowledge, this is the first paper to introduce experimental variation in order to satisfy the exclusion restrictions needed for sequential identification. Our approach resembles a selective trial as described by Chassang et al. (2012) in that the take-up decision reveals private information about farmer type. However, we use random variation in the take-up subsidy as opposed to incentive compatible mechanisms to reveal agent's information about her own returns. In addition, we allow for the information set available to the agent to change between the time the take-up decision is made and the time the follow-through decision is made. Along with this methodological contribution, our paper pulls together two distinct strands of literature: first, the literature on subsidies for technology adoption in development (e.g., Carter et al. 2014; Dupas 2014; Fischer et al. 2014), and second, the literature on investment under uncertainty (e.g., Pindyck 1993; Dixit and Pindyck 1994). ${ }^{15}$

The rest of the paper proceeds as follows. We begin with a simple theoretical model to generate intuition for the adoption problem. We turn in Section 3 to a description of the empirical context and experimental design, and show summary statistics and reduced form results in Section 4 . We present the empirical model and its identification in Section 5 and show estimation results and simulations in Section 6. Section 7 discusses the interpretation of the results, including learning and procrastination, and Section 8 concludes.

\section{A simple model of intertemporal technology adoption}

Consider a two period model, where each agent choses whether to purchase a single unit of a technology (take-up) in the first period (time 0) at a cost of $c$, and whether to follow-through with implementation of the technology in the second period (time 1). There is a net cost of complying, $F_{0}+F_{1}$, with only $F_{0}$ known to the agent at the time the technology is purchased. The remaining component of the cost, $F_{1}$, is random with known distribution to the agent at time 0 , and its realization is revealed to the agent at time $1 .{ }^{16} F_{0}+F_{1}$ can be interpreted as the "net cost" of following-through for the agent and can be positive (if costs outweighs benefits) or negative (if benefits outweigh costs). Note that although $F_{0}$ is known at time 0 , both $F_{0}$ and $F_{1}$ are incurred at

\footnotetext{
${ }^{15}$ A small number of other papers span these literatures. For example, Bryan et al. (2014) study a household's decision to migrate under uncertainty about the payoffs from doing so. They find substantial increases in migration and profits in response to a small subsidy for migration. More relevant to our context, Fafchamps (1993) studies the tradeoff between returns and flexibility in labor investments over the course of the agricultural season. Farmers choose flexible production plans that benefit from the value of information associated with delayed investments (see also Bontems and Thomas (2000); Magnan et al. (2011)).

${ }^{16}$ Note that because the distribution of $F_{1}$ is mean zero by construction since its distribution is known to the agent and it enters the profit function additively, thus any non-zero mean is known to the agent at time 0 and incorporated into $F_{0}$. Also note that the information revelation process can be one of learning about the technology itself or one of shock realization. The current model is forward-looking and relevant for both. Ex post, they diverge. As we move to our field setting, we will attempt to distinguish these two interpretations of the nature of the information.
} 
time 1. In addition to the private (or intrinsic) net costs faced by the agent, there could be external economic incentives to either take-up the technology (a subsidy, $A$ ) or to follow-through (a reward, $R$ ). We assume these, as well as the unsubsidized cost $c$, are constant across agents.

We assume linear utility - or risk neutrality - throughout the paper, including the empirical analysis. Although risk aversion is an important component of intertemporal decisions with costs or benefits that represent substantial shares of household income, our theoretical and empirical frameworks are best applied to technology adoption decisions that will cause relatively small changes to income. Importantly, our theoretical and empirical frameworks model decisions as a function of the profits associated with adoption relative to the best alternative use of household resources. Thus, a positive shock to the opportunity cost of adoption could correspond to an increase or a decrease in overall household income. Incorporating risk aversion into our theoretical model would require us to make modeling assumptions about the nature of the opportunity cost of adoption. For example, an increase in profitability of a competing economic activity and a labor shortage due to health could both represent an increase in the opportunity cost of adoption, but would have opposite effects on total income and thus on marginal utility of income. Hence, we prefer to leave the source of the opportunity cost unspecified, which makes our framework generalizable to any source of uncertainty to the extent that adoption decisions do not result in large changes in income. ${ }^{17}$

Following backward induction, the agent's decision at time 1 is whether to follow-through or not, and this decision is made to maximize her utility at each point in time. With a linear utility assumption, the net benefit derived by the agent in period 1 is given by $R-F_{0}-F_{1}$ if she choses to follow-through and 0 if she choses not to follow-through.

At time 0 , the agent's decision is whether or not to take-up by purchasing the technology. The agent chooses to take-up if

$$
c-A-\delta \mathbb{E}_{F_{1} \mid F_{0}} \max \left(R-F_{0}-F_{1}, 0\right)<0
$$

where $\delta$ is the one-period discount factor and the expectation in (1) is taken with respect to the conditional density of $F_{1}$ given $F_{0}$.

To simplify the exposition, assume $F_{0} \perp F_{1}$, and that the random net cost component takes one of two values

$$
F_{1}=\left\{f_{L}, f_{H}\right\}, \text { with } f_{L}<f_{H}, \text { and } \mathbb{E}_{F_{1} \mid F_{0}}\left(F_{1}\right)=\mathrm{g}_{1}\left(f_{L}\right) f_{L}+\mathrm{g}_{1}\left(f_{H}\right) f_{H}
$$

where $\mathrm{g}_{1}($.$) is the probability mass function of F_{1}$. The independence assumption on $F_{1}$ and $F_{0}$ implies that $g_{1}($.$) is constant across agents. Assume also that F_{0}$ is continuously distributed across agents with cumulative distribution function $\mathrm{G}_{0}(.){ }^{18}$

\footnotetext{
${ }^{17}$ In Section 5, we document that the size of the benefits derived from our program is small relative to total household income; and thus the risk neutrality assumption is unlikely to affect our conclusions.

${ }^{18}$ This model simplifies our empirical setting in two key ways: first, it assumes a binary follow-through decision and
} 
The distributional assumption on $F_{1}$ allows us to classify individuals into three types: those who never follow-through (hereforth non-adopters), those who follow-through only if the low net cost shock is realized (hereforth contingent adopters) and those who always follow through, regardless of the realization of $F_{1}$ (hereforth always adopters). These three types of agents can be characterized by their value of $F_{0}$ (what they know about their net costs at the time of take-up): non-adopters have the highest value of $F_{0}$ (between $R-f_{L}$ and $\infty$ ); contingent adopters have a mid-size value of $F_{0}$ (between $R-f_{H}$ and $R-f_{L}$ ); always adopters have the smallest value of $F_{0}$ (between $-\infty$ and $R-f_{H}$ ). Figure 1 graphically shows the proportions for each type of agent using areas under a symbolic bell-shaped distribution for $F_{0}$, separated by gray dashed lines. Figure 1 also illustrates two thresholds (along the support of $F_{0}$ ) for take-up in black dashed lines. The first take-up threshold (labeled $\left.R-\mathbb{E}\left(F_{1}\right)-\frac{c-A}{\delta}\right)$ is only binding if it falls to the left of the threshold that defines always adopters $\left(R-f_{H}\right)$. When this first take-up threshold binds, only always adopters take-up. The second take-up threshold (labeled $\left.R-f_{L}-\frac{(c-A)}{\delta g_{1}\left(f_{L}\right)}\right)$ is perhaps more interesting. When binding, it determines the full share of types that takes-up, which includes all always adopters and a subset of contingent adopters. We further use this figure to explain intuitively the results outlined by each of our propositions below. The formal proofs of these propositions can be found in Appendix A.1.

Proposition 1 Under low levels of uncertainty, follow-through conditional on take-up increases as a function of the total (potentially subsidized) take-up cost.

To see this, note that as take-up cost increases (represented by $c-A$ in Figure 1), the second take-up threshold moves to the left, bringing down the overall share of contingent adopters among the set of individuals who take-up. Since contingent adopters follow-through with probability less than one $\left(g_{1}\left(f_{L}\right)\right)$, this in turn increases the share of individuals who follow-through among those who take-up. Proposition 3 shows how this relationship weakens as uncertainty increases. ${ }^{19}$

Proposition 2 An increase in uncertainty reduces follow-through conditional on take-up.

Given the assumed distribution for $F_{1}$, an increase in uncertainty can be represented by an increase in the distance between $f_{L}$ and $f_{H}$. This, in turn, causes the share of contingent adopters to increase (as the two grey dashed lines move further apart). Note that as uncertainty increases, the position of the second take-up threshold does not change relative to the threshold that determines the upper bound for contingent adopters. Thus, contingent adopters become a larger share of those who take up, reducing average follow-through.

\section{Corollary 2.1}

second, it assumes a discrete distribution on $F_{1}$. As we show when we present our empirical model, the propositions derived from this model are not an artifact of the distributional assumption on $F_{1}$ nor of the binary decision that characterizes follow-through in this simple model. The independence assumption between $F_{0}$ and $F_{1}$ can be thought of as an assumption on how uncertainty enters profits in the model: in an additive way.

${ }^{19}$ If the take-up cost, $c-A$, increases enough that the first take-up threshold becomes binding, follow-through conditional on take-up reaches 100 percent and stays constant for further increases in the take-up cost. 
Under no uncertainty, everyone who takes-up follows-through.

This is easy to see from figure 1 , as under no uncertainty (where $f_{L}=f_{H}$ ) there would be only always adopters and never adopters.

Proposition 3 An increase in uncertainty weakens the relationship between take-up cost and conditional follow-through shown in Proposition 1.

To see this, visualize the take aways of Propositions 1 and 2 simultaneously in the graph. Under a high level of uncertainty (recall uncertainty expands the number of contingent adopters while keeping the relative position of the second take-up threshold and the $R-f_{L}$ line constant), the take-up cost is less effective at deterring contingent adopters from taking-up. More precisely, the share of contingent adopters that are excluded by an increase in the take-up cost becomes a smaller proportion of all those who take-up when uncertainty increases.

Proposition 4 The option value associated with take-up is increasing in uncertainty, which results in higher take-up at all take-up cost levels.

We define option value as the difference between value of a dynamic contract (with a two-period decision framework, as outlined above) and a static contract (where take-up and follow-through decisions are made simultaneously at time 0$):{ }^{20}$

$$
O V\left(F_{0}\right)=\mathbb{E}_{F_{1} \mid F_{0}} \max \left(R-F_{0}-F_{1}, 0\right)-\max \left(\mathbb{E}_{F_{1} \mid F_{0}}\left(R-F_{0}-F_{1}\right), 0\right)
$$

Under this hypothetical static contract, a farmer would be required to stick to a decision on followthrough made jointly with the take-up decision. The value of the static contract (second term to the right of the equal sign in 2) does not vary with uncertainty: the symmetric distribution of shocks means that the ex post expected profit does not increase (or decrease) with the variance of the shock. Thus, this result also implies that there is a positive relationship between the expected profit of the contract and uncertainty stemming solely from the response of the option value to uncertainty.

In the appendix, we show how this quantity increases with uncertainty and has an asymmetric relationship with the upper and lower bounds of the $F_{1}$ distribution. Intuitively, the option value is the value of "reoptimizing" after the take-up decision is made and the new information (the realization of $\left.F_{1}\right)$ emerges. As uncertainty $\left(f_{H}-f_{L}\right)$ increases, the gains from follow-through conditional on a low cost shock $\left(f_{L}\right)$ increase. Because agents can choose not to follow through, $f_{H}$ is less important in determining the take-up decision. Thus, an increase in uncertainty increases the option value of the contract, resulting in higher take-up.

\footnotetext{
${ }^{20}$ This corresponds most closely to the "value of waiting" in Dixit and Pindyck's (1994) framework, when the decision is over whether to abandon a project.
} 


\subsection{Common Shocks, Transitory Shocks and Learning}

So far, we have left open the question of whether $F_{1}$ should be interpreted as a permanent or a transitory shock. That is, if the $F_{1}$ component of the returns to the technology is permanent, the agent will learn about it in period 1 and will incorporate it into future choices about the technology. If $F_{1}$ is transitory, the same decisions in the future will have the same level of uncertainty and the same option value associated with take-up as when the technology is introduced for the first time. Note that the interpretation does not matter for the exposition so far, since we restrict our attention to the first instance a new technology is introduced. However, incorporating the private and social value of future take-up and follow-through decisions could change conclusions regarding the optimal take-up level. We cannot completely disentangle these two interpretations of the model in our context, though we use survey data to provide suggestive evidence on the extent of learning (see Section 7).

In addition, we have not specified whether $F_{1}$ represents common or idiosyncratic shocks. This distinction does not play a role in the analysis so far, since farmers can form expectations on either type of shock as long as they have knowledge of its distribution. However, this distinction will play a more important role in the empirical framework. Thus, it is illustrative to understand how common and idiosyncratic shocks will affect cross-sectional variation in outcomes using this simple theoretical model. Assume all farmers face the same distribution of $F_{1}$. If $F_{1}$ represents a common shock, all farmers will have the same realization (either $f_{H}$ or $f_{L}$ ) of the shock ex-post. Hence, all contingent adopters will either follow-through (if $f_{L}$ is realized) or not (if $f_{H}$ is realized), i.e. a common shock does not translate into cross-sectional variation in follow-through choices among contingent compliers, while idiosyncratic shocks do. Note, however, that the cross-sectional variation in the take-up decision is unchanged by the nature of the shock.

\section{Context and experimental design}

We bring the propositions from our conceptual model to a two part technology adoption problem, characterized by uncertainty in the costs and benefits of following through with the technology. In the context of an ongoing project to encourage the adoption of agroforestry trees (Faidherbia albida), we introduce exogenous variation in the payoffs to farmers at the time of their take-up and followthrough decisions. Our ultimate goal is to use experimental variation to uncover the existing levels of static heterogeneity and uncertainty in the population of farmers, which we model as random parameters. This design relies on orthogonal assignment to treatments that affects farmers at two different points in time to reveal how farmers' cost-benefit calculation, and therefore the information they have, changes between the first (take-up) and second (follow-through) decisions. This section describes the context and the experimental design in detail and Section 4 shows some reduced form results that provide simple empirical facts consistent with the presence of uncertainty. We discuss 
identification assumptions and estimation of the structural model in more detail in Section 5 .

The study was implemented in coordination with Dunavant Cotton Ltd., a large cotton growing company with over 60,000 outgrower farmers in Zambia, and with an NGO, Shared Value Africa. The project, based in Chipata, Zambia, targeted approximately 1,300 farmers growing cotton under contract with Dunavant, alongside other subsistence crops. The project is part of the NGO partner's portfolio of carbon market development projects in Zambia.

\subsection{The technology}

Faidherbia albida is an agroforestry species endemic to Zambia that fixes nitrogen, a limiting nutrient in agricultural production, in its roots and leaves. Optimal spacing of Faidherbia is around 100 trees per hectare, or at intervals of 10 meters. The relatively wide spacing, together with the fact that the tree sheds its leaves at the onset of the cropping season, means that planting Faidherbia does not displace other crop production (Akinnifesi et al. 2010). Agronomic studies suggest significant yield gains from Faidherbia. However, these private benefits take 7-10 years to reach their full value, and may be insufficient to justify the up-front investment costs. Indeed, a back of the envelope estimate suggests that, at the high discount rates typically observed in developing country settings, the adoption of Faidherbia is not a privately profitable investment for most farmers. Average benefits for adoption on half a hectare of land are around USD 2 and average costs around USD 19. ${ }^{21}$ Negative net benefits, on average, are consistent with the low adoption rates we observe at baseline: less than 10 percent of the study households reported any Faidherbia on their land. ${ }^{22}$

Subsidies may therefore be necessary to increase take-up rates, and are justified by positive environmental externalities and market failures that contribute to high private discount rates. Environmental benefits include erosion control, wind breaks, and carbon sequestration. Based on allometric equations from Brown (1997), adapted to the growth curves for Faidherbia, we estimate that over the course of 30 years, a tree sequesters around 4 tons of carbon dioxide equivalent. Discounting the annual sequestration at 15 percent leads to a present value of around 0.48 tons. At a marginal social cost of carbon of $21 \mathrm{USD} /$ ton, the present value of sequestration associated with

\footnotetext{
${ }^{21}$ Agronomic studies suggest yield gains from planting Faidherbia range from 100 to 400 percent, relative to production without fertilizer (Saka et al. 1994; Barnes and Fagg 2003), corresponding to income gains of up to USD 400 per hectare per year. For our back of the envelope calculation, we take mid-range values from the literature and assume that yields on half a hectare of land increase by 525 kilograms, starting 10 years after trees are planted. At current maize prices, this equals additional income of 136.50 USD per year from years 10 to 20 . At a discount rate of 0.67 , which is based on survey data and the literature, the present value of this investment is USD 2.02. While this discount rate is high, it is in line with observed interest rates and elicited individual discount rates in rural developing country settings (Conning and Udry 2007; Cardenas and Carpenter 2008). It corresponds to a discount factor of 0.6, which we employ in the structural model. With respect to the private costs, surveys implemented in conjunction with our study indicate that farmers invest around 38 hours planting and caring for the trees. At an agricultural wage rate of around USD 2.5 per day, these time investments correspond to USD 19 of labor costs incurred in the first year.

${ }^{22}$ Informal land tenure in the project area presents an additional barrier to adoption. By focusing on landholders engaged in contract farming arrangements, the project targets households with relatively secure tenure.
} 
half a hectare of surviving trees is around USD 353.

Both the private and the public benefits associated with adoption require that farmers continue to invest in the technology, even after their initial take-up decision is made. To obtain the private and public benefits, farmers must plant, water, weed and otherwise care for the trees, activities that are costly in the short run. In addition, the opportunity cost of these investments may be highly uncertain and depend on shocks to household labor supply, weather, pests and prices, all of which are realized after the initial take-up decision is made. Therefore, the technology maps clearly onto our conceptual framework, with farmers deciding whether or not to follow-through by choosing whether to continue to invest in keeping trees alive after the initial take-up decision.

\subsection{Experimental design and randomization}

Our experimental design serves two purposes. First, the treatments allow for reduced form tests for the presence of uncertainty about the costs and benefits of follow-through at the time of the farmer's take-up decision stemming from our conceptual model in Section 2. Second, the experimental variation identifies a structural model of intertemporal technology adoption under uncertainty. The study design varied two major margins of the farmer's decision to adopt Faidherbia albida. All farmers were given a take it or leave it offer of a fixed number of seedlings (50, or enough to cover half a hectare) to be planted and managed by the farmer and his or her household. The cost of the seedlings (the take-up decision) was subsidized in some cases. The program offered a threshold payment conditional on follow-through (tree survival) after one year (time 1). Farmers received the reward if they kept 70 percent (35) of the trees alive through the first dry season (for 1 year). The threshold reward, as opposed to a per-tree incentive, allows us to draw a sharper distinction between internal incentives and external incentives to cultivate the trees, which aids identification of the structural model. ${ }^{23}$ We collected data on the binary take-up decision, the number of trees that survived after a year (whether or not this number was above the 35-tree threshold) and whether or not the farmer earned the reward associated with the 35-tree threshold.

Because the threshold reward pays out after a year after which no further incentives for tree survival are offered, farmers' decisions on take-up and follow-through are based on their perceptions about costs and benefits during the first year only. The first year is the most relevant on the cost side, since the costs associated with planting and caring for the trees are highest during the first year when the trees are vulnerable and require substantial attention in the form of watering, weeding and protection from pests. After they survive the first dry season, costs decrease substantially. The follow-through decision we observe is more accurately described as the cumulative outcome from

\footnotetext{
${ }^{23}$ In addition to its advantages in our empirical design, the threshold reward was easy to enforce, consistent with other related contracts offered by Dunavant, and easy to explain to the farmers. The threshold was chosen based on Faidherbia survival rates in other programs in Eastern Zambia. Specifically, for a sample of around 3000 farmers tracked by another NGO, which offered no performance incentive, a 70 percent survival rate was achieved by around 20 percent of farmers.
} 
numerous follow-through decisions made over the course of the year after take-up. New information may reveal itself starting immediately after the take-up decision is made, or gradually, as family members fall ill, crops fail, or input and output prices change. ${ }^{24}$ Each time new information arrives that affects the opportunity cost of caring for the trees, farmers may reoptimize on the number of trees they continue to cultivate (if any). Therefore, at the time that we measure follow-through, we observe the cumulative effect of all of these decisions. On the benefit side, we expect to see little change in information within the first year since the private benefits take considerably longer than the costs to materialize. Of course, farmers may still face uncertainty about the costs and benefits of keeping trees alive, even after follow-through is measured. ${ }^{25}$

Figure 2 summarizes the experimental design. First, the size of the take-up subsidy $(A)$ was varied at the farmer group level in increments of 4,000 ZMK from a subsidy of 12,000 ZMK (fully subsidized) to zero. At zero subsidy, farmers paid 12,000 ZMK (approximately USD 2.60) for inputs, which is the cost recovery price for the implementing organization. Groups were randomly assigned to one of four take-up subsidy treatments using the min max $\mathrm{T}$ approach (Bruhn and McKenzie 2009), balanced on Dunavant shed, farmer group size and day of the training. Second, the size of the threshold performance reward $(R)$ was varied at the individual level, in increments of 1,000 ZMK, ranging from zero to 150,000 ZMK or approximately 30 USD. ${ }^{26}$ Variation in the reward was introduced using a random draw at the time of the take-up decision. One-fifth of all draws were for zero ZMK with the remaining four-fifths distributed uniformly over the range.

Third, the timing of the reward draw was varied at the individual level to occur either before or after (a surprise reward treatment) the farmer's take-up decision. The timing was pre-determined based on the registration number. A roughly equal number of farmers were assigned to each timing treatment ( $52.5 \%$ were assigned to the surprise reward treatment). Recall from Section 2 that $R$ has a direct effect on both the take-up decision and the follow-through decision, while $A$ affects followthrough only via its effect on the types of agents who choose to take-up. We use the variation in the timing of when the reward was announced to separate the effect of $R$ on take-up and on follow-through, in a similar spirit to Karlan and Zinman (2009). ${ }^{27}$ This third source of variation also provides an additional test for liquidity constraints as a driver of selection outcomes.

\footnotetext{
${ }^{24}$ The take-up decision is made at the beginning of the planting season. This is the natural timing of take-up decisions for other crops and technologies. Therefore, our design allows for an amount of time between take-up and follow-through that is similar to many other agricultural technologies.

${ }^{25}$ As mentioned in the previous section, the fertilizer benefits of the technology do not appear until years 7-10. The only potential for learning during the course of the experiment is therefore about the costs associated with keeping trees alive, which is an activity similar to what most farmers do each year with other crops.

${ }^{26}$ At the time of the study, the exchange rate was just under $5000 \mathrm{ZMK}=1$ USD. In piloting, the distribution of payments extended to 200,000 but was scaled back prior to implementation. The scratch cards with values between 150,000 and 200,000 were removed from the prepared cards by hand, but six of them were missed. For the main analysis, we top-code payments at 150,000 .

${ }^{27}$ We do not manipulate or measure beliefs about potential financial benefits from joining in the surprise reward treatment, and cannot therefore assume that farmers in the surprise reward treatment assumed $R=0$ at the time of take-up.
} 


\subsection{Data and implementation}

The field experiment was implemented between November 2011 and December 2012 with 125 farmer groups and around 1300 farmers. Implementation of the study relied on Dunavant's outgrower infrastructure, which is organized around sheds, each of which serves several dozen farmer groups. The farmer groups consist of 10-15 farmers and a lead farmer, who is trained by Dunavant each year and in turn trains his or her own farmers on a variety of agricultural practices. The study included the following stages: farmer training, program enrollment, baseline survey, end line survey, tree monitoring, reward payment. We describe each of these stages in turn.

\section{Farmer training}

Lead farmers attended a training on Faidherbia at their Dunavant shed, which provided them with the information and materials necessary to train their own farmer groups. ${ }^{28}$ The group trainings were scheduled by the project team for approximately four weeks after the lead farmer training and were attended by study enumerators. Either the household head or an immediate family member participated in the group training, as per Dunavant's usual practices. At the group training, farmers were provided with instructions on planting and caring for the trees, were given information about the private fertilizer benefits and public environmental benefits of the trees, and were informed about the eligibility requirements for the program. ${ }^{29}$ All farmers who attended the group training received a show up fee of 12,000 ZMK and lunch.

\section{Program take-up}

After the technical training, study enumerators explained the details of the adoption decision, including the cost of the inputs $(12,000 \mathrm{ZMK}$ minus the subsidy), which was announced to all farmers as a group. The un-subsidized price $(12,000 \mathrm{ZMK})$ is approximately one day's agricultural wages. To implement the individual-level randomization of the rewards and allow participants to make their take-up decision in private, the study enumerators called the farmers aside one by one. The farmer was told that he could earn a reward conditional on reaching a threshold of 70 percent tree survival after one year. The farmer then drew a scratch off card from a bucket, which revealed the individual reward value, after which the take-up decision was recorded. The surprise reward treatment proceeded similarly, but the take-up decision was recorded before the farmer was informed

\footnotetext{
${ }^{28}$ As described above, this is standard practice. At the lead farmer training, study enumerators collected basic information from the lead farmers for input into the randomization. Thus, any selection into the Faidherbia training by lead farmers is orthogonal to treatment. In addition to training their own farmers, lead farmers were responsible for constructing a nursery in their community, and were paid for the labor and materials. Backup nurseries were also constructed at the Dunavant sheds.

${ }^{29}$ Eligibility required that land must have been un-forested for 20 years, must be owned by the farmer, and must not be under flood irrigation. Study enumerators confirmed that all lead farmers covered the necessary training material and summarized the main points at the end of the training to ensure that all farmers had accurate information.
} 
about the threshold reward. Conditional on agreeing to join the program, the farmer was told about the rewards and given the opportunity to draw a scratch card. After the value was revealed, farmers could change their minds about take-up. No one did.

\section{Survey data}

Following the take-up decision, all farmers were given a baseline survey that lasted for approximately one hour. Of the 1314 farmers for whom a participation decision was recorded, 1292 are in the baseline survey sample. After the survey, participating farmers signed a contract indicating their agreement with the program terms, paid the take-up cost and collected their seedlings. ${ }^{30}$

Two additional data collection instruments were administered between the baseline and endline surveys. First, one-fifth of the farmers were randomly sampled for ongoing visits to collect information on activities and inputs associated with the contract and with other crops. These visits, which we refer to as effort monitoring, consisted of a very short survey ( 20 minutes), during which a project monitor asked the farmer about agricultural activities, including those related to the trees, since the last visit. No information was provided to the farmers about their performance and monitors were instructed not to prompt specific activities or answer technical questions. We control for the effort monitoring subsample in our analysis, but do not analyze its effects on program outcomes. Second, all farmers were visited at the end of the planting season for a very brief survey on seedling pick up, transplanting and care, primarily for the purpose of obtaining qualitative information about the timing of planting and tree care activities. Together, the planting and monitoring results indicate two important facts about the timing of farmer investments. First, planting activities began immediately after the training for some farmers, while other farmers chose to delay tree planting until other crops were planted and the rainfall patterns were clearly established. Second, tree care activities spanned the entire agricultural season and tapered off before the tree survival monitoring one year after training, consistent with the need for ongoing investments on the part of the farmer.

All farmers in the study sample were given an endline survey, regardless of their decision to participate in the contract. Of the 1292 farmers in the baseline survey, 1232 (>95 percent) are also in the end line survey.

\section{Tree survival monitoring and reward payments}

One year after program enrollment, we measured tree survival outcomes and disbursed rewards to those who had at least 35 surviving trees. Approximately one week after the endline survey, farmers with contracts were visited for field monitoring, during which the farmer and a study enumerator examined each tree, and recorded whether it was sick, healthy or dead. Monitors also recorded

\footnotetext{
${ }^{30}$ Some farmers chose to leave their seedlings with the lead farmer for later collection. In a small number of cases, the lead farmer's nursery had not generated enough seedlings to support the group. In those cases, seedlings from a backup nursery were transported to the site.
} 
whether they observed indicators of activities likely to affect survival outcomes. Specifically, the monitor recorded a binary indicator of signs of weeding, watering, constructing fire breaks, and field burning. The first three improve tree survival; the third is a threat to tree survival. All surviving trees counted toward the tree survival threshold. In case of disputes, a third party was called in from the village.

Finally, within a couple of days of the monitoring visit, the reward payment team visited each farmer group and paid the rewards to farmers with 35 or more surviving trees. Keeping the payments separate from the monitoring was intended to improve the monitors' objectivity. ${ }^{31}$ Of the farmers eligible for monitoring, we were unable to locate 9 of them and thus assume zero tree survival in the analysis.

\section{Summary statistics and reduced form results}

\section{Sample characteristics}

Appendix table A.1 shows baseline summary statistics. Around 70 percent of participants are heads of household and 13 percent of households are female headed. Respondents have, on average, just over 5 years of education and live in households with just over 5 members. Households have around 3 hectares of land spread across just under 3 fields, which are an average of around 20 minutes away from their dwelling. Around 10 percent of households state that soil fertility is one of the major challenges that their household faces. Households have worked with Dunavant Cotton for an average of over 4 years and over 40 percent interact regularly with their lead farmer. Very few are affiliated with other local organizations that promote Faidherbia albida (CFU and COMACO). Almost 70 percent of respondents report familiarity with the technology but only around 10 percent had adopted prior to the program.

\section{Balance and attrition}

We test the randomization outcomes by comparing observable characteristics across treatment groups. Appendix table A.4.1 tests balance for the take-up subsidy, threshold performance reward, and surprise reward treatment. We observe some imbalance in the assignment of the take-up subsidy treatment with slightly larger households with more non-agricultural assets receiving lower take-up subsidy assignments on average. We also observe that older respondents with larger households and better self-reported soil fertility are marginally more likely to be assigned to the surprise

\footnotetext{
${ }^{31}$ As a check for collusion between the monitors and farmers, we test whether individual monitors are associated with a higher probability that a farmer passes the tree survival threshold. No single monitor indicator is significantly correlated with reaching the threshold, nor are the monitor indicators jointly predictive. This implies that either all monitors were cheating to the same degree or that no monitors were cheating. Given differences in career concerns with the study implementers (some had higher paid jobs as survey supervisors when not engaged in monitoring), cheating by all monitors is unlikely.
} 
reward treatment. The table tests balance for 17 variables and consists of 51 separate regressions. Five significant coefficients is therefore consistent with significance threshold of 10 percent.

We also examine whether non-random attrition may undermine internal validity. ${ }^{32}$ We examine attrition at each stage of data collection in Appendix table A.4.2. Take-up rates in the baseline survey are over 98 percent, while the end line included 94 percent of all study farmers and over 95 percent of baseline respondents. We see some evidence that farmers who received lower take-up subsidies were marginally less likely $(p<0.10)$ to participate in the surveys. Otherwise, attrition is balanced across treatments. For the tree survival monitoring, over 95 percent of the 1092 households that took up the program were located.

Finally, spillovers across treatments pose a threat to the experimental design. Because the takeup subsidy treatment was assigned at the group level, spillovers are relatively unlikely. During regular effort monitoring visits, no farmers asked about differences in take-up costs. The value of the threshold reward, on the other hand, varied at the individual level within-group. By revealing the reward value privately to each farmer before the take-up decision, we mitigate the potential that take-up is affected by rewards received by others. ${ }^{33}$ However relative reward values may still affect performance since farmers can share information after they leave the training. We observe some suggestive evidence that a higher average reward among other farmers in the group has a positive spillover on own survival probabilities, though the magnitude of the effect is small relative to the direct effect of the reward. ${ }^{34}$

\footnotetext{
${ }^{32}$ Selection into treatment is also a threat to the experiment's internal validity. By design, this is unlikely: group level participation subsidy treatments were revealed only after individuals arrived for training, and individual-level reward treatments were assigned in a one-on-one interaction with study enumerators.

${ }^{33}$ This is confirmed empirically by regressing the probability of take-up on the average random reward draw that preceded a farmer's own draw. The outcomes of preceding draws have no effect on the probability of take-up.

${ }^{34}$ Randomization of rewards at the individual level also gives rise to concerns about reselling seedlings to those with higher rewards or transplanting young trees just before monitoring. We use several pieces of information to investigate these concerns. First, we would expect that take-up would reflect the potential to re-sell if farmers were aware of the individual-level variation in rewards. In other words, farmers that were aware of the arbitrage opportunities generated by the variation in the reward treatment should be more likely to take-up, and increasingly so as the size of the subsidy falls (i.e. would respond less to the subsidy). However, a regression of take-up on the interaction of the surprise reward treatment and the level of the take-up subsidy shows no significant interaction or clear pattern of coefficients. Second, to investigate the potential for transplanting, we take advantage of planting data collected for all farmers shortly after the end of the rainy season. We construct a measure of the difference between the planting and the monitoring tree counts, which is positive for around 100 farmers. The positive value indicates either very delayed planting or transplanting. Restricting attention to those with a positive value, the coefficient from regressing this measure of extra trees on the size of the reward is insignificant, and becomes negative (and insignificant) when group fixed effects are included. Third, we examine the within-group spillovers associated with the effect of the reward on tree survival outcomes. To the extent that transfers of any kind are happening within group, we expect a steeper slope on the reward within-group than on average. We observe a slightly smaller and statistically indistinguishable coefficient on the reward when group fixed effects are included, relative to the coefficient without fixed effects. Appendix table A.4.3 shows spillover effects of the rewards.
} 


\subsection{Reduced form results}

We examine the data for four pieces of reduced form evidence. First, we examine how the incentive offered by the threshold reward affects tree survival outcomes and also indicators of farmer investments in the trees. Second, we look for reduced form evidence consistent with the presence of uncertainty. Third, we explore whether liquidity constraints affect take-up and therefore selection into the program. Fourth, we turn to more behavioral explanations for our results.

\section{The effect of economic incentives on follow-through and farmer investments}

We first show that farmers' follow-through choices are responsive to economic incentives. Table 1 displays means and standard deviations for several program outcomes: take-up, follow-through (tree survival $\geq 35$ ), zero surviving trees and the number of trees conditional on positive survival rates. These statistics are broken down by treatment and show clear patterns in responses to the incentives offered in the experiment.

There is a positive effect of the reward amount on follow-through, whether we focus on the likelihood that farmers reach the 35-tree threshold or the absolute number of trees. This can be seen first in Panel C of Table 1, which in column 2 shows that the share of farmers that reached the 35-tree threshold increases from 0.13 to 0.32 across reward groups in ascending order, and in column 3 shows a similarly monotonic relationship between the number of trees and the reward amount. Column 4 also shows that the share of farmers with zero surviving trees falls monotonically with the reward. We also look at the linear relationship between these three outcomes and the reward when we compare our data with the structural estimates (see Table 4). For example, the reward amount (in '000 ZMK) has a marginal effect of 0.044 surviving trees that is significant at the 1 percent level (column 7 of Panel A). ${ }^{35}$

Consistent with the follow-through results, we find evidence that farmers' investment choices are responsive to the reward. Table 2 shows the relationship between farmer activities recorded by enumerators during the field monitoring visits and the reward amount. Each of the outcomes is a binary indicator for whether the monitor observed signs of weeding, fire breaks, watering and burning. All of these activities are costly to the farmer and are likely to affect tree survival. The first three are likely to improve tree survival, while the fourth poses a (manageable) threat to tree survival, but provides short run benefits to other crops growing on the field. Note that these outcomes are recorded at the end of the contract period and do not necessarily reflect farmer investments at other points during the year; we therefore view these results as supplementary to our results on tree survival. Panel A includes only non-missing observations. Farmers that reported

\footnotetext{
${ }^{35}$ The relationship between follow-through and the reward is entirely driven by the cost-benefit calculation among farmers who took up, and not by selection into the program based on reward amounts. We can show this by comparing the response to the reward across farmers who learned about the reward after choosing to take-up and farmers that knew about the reward before taking-up. The marginal effect of the reward is statistically similar in the two groups (see Appendix Table A.4.5).
} 
zero surviving trees during the endline survey did not receive a field visit, and as a result, we do not observe whether they undertook these activities. In addition, in 14 cases, all but one of which had zero surviving trees, the enumerator did not record the outcomes. Panel B replaces missing observations with zeros, which is valid if farmers with zero surviving trees were not undertaking these activities at the time of tree monitoring.

Panel A shows that the reward threshold increases the probability that the enumerator observed weeding, fire breaks and watering, with p-values of $0.059,0.129$, and 0.041 respectively. We interpret the effect of the reward as causal, given that we do not observe any evidence of selection effects of the reward, as described below. The coefficient on field burning, which threatens tree survival, is negative and statistically insignificant. Panel B shows stronger effects of the rewards on the beneficial farmer investments (columns 1-3), some of which is likely to be mechanical since farmers with zero trees who were not visited are assigned a value of zero. Consistent with this, in Panel $\mathrm{B}$, we observe a weak positive relationship between field burning and the reward. These findings indicate that farmers who received a higher reward were also more likely to invest in activities to increase tree survival.

\section{Reduced form evidence of uncertainty}

We use the means and standard deviations presented in Table 1 to provide evidence for the presence of uncertainty, consistent with our conceptual model. Regression-based results are shown in Table 4. First, notice that take-up rates are increasing across values of the take-up subsidy. Take-up rates are high, on average, even in the zero subsidy condition, where over 70 percent of farmers take-up. This could be due to high known payoffs from follow-through, on average, or to high expected values driven by option value (see Proposition 4).

Second, we observe that follow-through rates vary considerably within subsidy and reward treatments and are low, on average, with only 25 percent of farmers reaching the 35-tree threshold (column 2). This holds even in the zero subsidy condition, ruling out that farmers were certain about high payoffs associated with cultivating a large number of trees at the time of take-up. Low follow-through conditional on take-up is consistent with Proposition $2 .^{36}$

Third, a large number of farmers abandon the technology altogether (have a survival of zero trees), even conditional on taking up with zero subsidy (37 percent, column 4). This rules out that farmers were certain about positive payoffs from a small number of trees at the time of take-up, and is consistent with Corollary 2.1 of our conceptual model.

Finally, we see no reduced form effect of the subsidy treatment on the likelihood of reaching the 35-tree threshold or of abandoning the technology (zero trees). More formally, we implement a

\footnotetext{
${ }^{36}$ Behavioral explanations such as over-optimism or procrastination might also be consistent with high take-up and low-follow through, even at positive take-up prices. We discuss behavioral explanations consistent with the reduced form results, as well as the interpretation of the type of new information, in Section 7.
} 
two-sample t-test for equal means between the highest and lowest subsidy condition. For continuous tree survival, the probability of reaching the threshold ( $\geq 35$ trees) and zero trees, the p-values are $0.63,0.25$ and 0.32 , respectively. The linear regression test of the effect of the take-up subsidy on tree survival outcomes (shown in Table 4) is also statistically insignificant. This is consistent with Proposition 3, which states that the selection effect of subsidies will be diminished by high levels of uncertainty in the net benefits of follow-through.

We also examine whether outcomes can be explained by observables. Appendix Table A.4.4 shows that, overall, observables explains relatively little of the variation in outcomes: the R-squared from a regression of outcomes on observables is $0.0296,0.0297$ and 0.0314 for take-up, reaching the 35-tree threshold and tree survival, respectively. Adding the treatment variables improves the explanatory power substantially (even numbered columns). The low explanatory power of observables further motivates our use of a structural model to estimate the heterogeneity across farmers at both take-up and follow-through.

\section{Alternative mechanisms: Liquidity constraints}

Our design allows us to address concerns that liquidity constraints complicate the relationship between the take-up decision and farmers' expected payoffs at the time of take-up. We do this in two ways. First, as noted above, all farmers received a training show up fee sufficient to cover the cost of take-up in even the lowest subsidy treatment. Thus, cash-on-hand is unlikely to interfere with take-up. Second, the variation in the timing of the reward for follow-through provides a separate test for self-selection, which does not depend on immediate concerns about liquidity. Specifically, because some farmers were aware of the rewards at the time of the take-up decision and some were not, self selection based on expected payoffs should also incorporate the value of the reward. Importantly, the reward is paid after a year, and thus the response to it at the time of take-up should not be contaminated by immediate liquidity constraints. We see no difference in the response of follow-through to the value of the reward based on the timing of the reward announcement (see Appendix Table A.4.5). This provides further support for the conclusion that the new information after take-up plays a substantial role in the follow-through decision.

\section{Alternative mechanisms: Sunk cost, information signaling and crowding out effects}

Previous studies of the effect of subsidies on follow-through, via screening on private benefits, have worried about psychological effects associated with the initial price paid for the technology. First, sunk cost effects would cause higher follow-through among adopters who pay for more take-up, because adopters would consider their expenditure at take-up when making their follow-through decision (Ashraf et al. 2010; Berry et al. 2012; Cohen and Dupas 2010). Second, farmers could extract information about the quality of the technology from the NGO's decision to subsidize (Ashraf et al. 
2013). If higher subsidies accompany better technologies, then farmers in a higher subsidy condition might have a higher follow-through (tree survival). This works in the opposite direction as the sunk cost effect. Third, if paying farmers to take up the technology crowds out their intrinsic motivation for the technology, we might see higher subsidies leading to lower follow-through (Ashraf et al. 2014). This crowding out effect would work in the same direction as the sunk cost effect. Because we observe no effect of the exogenous variation in take-up subsidies on follow-through, we are able to rule out all three of these explanations. ${ }^{37}$ Note that were we to observe a screening effect of the take-up price, we would not be able to distinguish it from these other channels using our design.

\section{Model, identification and estimation}

The reduced form results and stylized facts in Section 4 provide evidence that is consistent with uncertainty in the opportunity costs of follow-through. However, they do not rule out that, in addition to uncertainty, other sources of heterogeneity in costs may explain part of the apparent disconnect between high take-up rates and low follow-through. This could be the case if, for instance, there is a negative correlation between the privately optimal number of trees and the private net profit derived from them. ${ }^{38}$ In addition, the reduced form results do not offer any specific facts about the magnitude of the uncertainty that farmers face and how does it compare to a set up where selection effects are present.

We modify our simple theoretical model described in Section 2 to adapt it to our empirical setting and explicitly estimate the distribution of random parameters governing a quasi-profit function (a "reduced form" profit function of sorts). This expanded model allows us to answer the questions above.

\subsection{Farmer net benefits}

We begin with a general characterization of farmer profits at $t=1$, after new all relevant information is revealed. Then we specify a time line for information and introduce the technology take-up decision under uncertainty (at $t=0$ ).

\footnotetext{
${ }^{37}$ That we do not see differences in follow-through across the reward timing conditions provides additional evidence against crowding out of intrinsic motivation associated with selecting in to the program based on expectation of a reward.

${ }^{38} \mathrm{~A}$ correlation (positive or negative) between the privately optimal number of trees and the level of profit can emerge from the joint distribution of the primitive parameters that govern a profit function (e.g. marginal costs, fixed costs, marginal benefits, etc.). This is somewhat similar to Suri (2011), who finds that low adoption rates of hybrid maize among farmers who seem to have high returns from adoption can be traced to a positive correlation between costs and benefits from adoption using a random coefficients model.
} 
General profit function Consider the decision of a farmer to plant and care for trees for their private benefits. We preserve the assumption of risk neutrality made in Section $2 .{ }^{39}$ Thus, we can represent farmer's utility from trees in terms of a profit function. Consider a general quadratic profit function for a number of trees $N$ given by

$$
\Pi(N)=\left[\sum_{t=7}^{\bar{T}} \frac{1}{(1+r)^{t}}\left(\alpha_{0} N-\alpha_{1} N^{2}\right)\right]-\gamma_{0} N-\gamma_{1} N^{2}-\gamma_{2} \times \mathbf{1}(N>0)
$$

where $\alpha_{0}$ and $\alpha_{1}$ are private benefit parameters, $r$ is the annual discount factor, $\bar{T}$ is the maximum number of years a tree lives, $\gamma_{0}$ and $\gamma_{1}$ are cost of implementation parameters that are proportional to the number of trees and $\gamma_{2}$ is a fixed cost of implementation. Recall that private benefits in the form of soil fertility start around the 7 th year. Under some parameter values, ${ }^{40}$ equation (3) describes a convex function in the number of trees cultivated. This is consistent with our empirical observation that a number of farmers find it optimal to cultivate a number of trees between zero and 50 (the number of seedlings they receive) in the absence of an external incentive (i.e. when the reward for tree survival is equal to zero). In other words, there the privately optimal number of trees appears to correspond to an interior solution to the private profit maximization problem for many farmers.

The solution to the profit maximization problem defined by (3) is:

$$
N^{*}= \begin{cases}\frac{\tau \alpha_{0}-\gamma_{0}}{2\left(\tau \alpha_{1}+\gamma_{1}\right)} & \text { if } \frac{\left(\tau \alpha_{0}-\gamma_{0}\right)^{2}}{4\left(\tau \alpha_{1}+\gamma_{1}\right)}-\gamma_{2}>0 \\ 0 & \text { if } \frac{\left(\tau \alpha_{0}-\gamma_{0}\right)^{2}}{4\left(\tau \alpha_{1}+\gamma_{1}\right)}-\gamma_{2} \leq 0\end{cases}
$$

where $\tau=\sum_{t=7}^{\bar{T}} \frac{1}{(1+r)^{t}}$. Thus, in this version of the model the follow-through decision corresponds to the choice of the optimal number of trees.

Note that, in principle, all parameters in $(3), \alpha_{0}, \alpha_{1}, \tau, \gamma_{0}, \gamma_{1}$, and $\gamma_{2}$, may vary across farmers. Our experimental variation, however, does not allow us to separately identify all potential sources of

\footnotetext{
${ }^{39} \mathrm{As}$ is discussed in Section 2, this assumption will have little consequence for our results to the extent that the changes in income produced by our program are small relative to total income. This is indeed the case, as the highest reward from our program is roughly 3.5 percent of average annual income. Although our baseline survey did not collect comprehensive measures of income, we know that the average annual income from the household's main crops has a mean of ZMK 2.4 million (s.d. ZMK 3.4 million), which is 16 times the maximum reward derived from our program and 34 times the average reward. This measure of income is likely to underestimate total income substantially, since it ignores income from minor crops, consumption value from subsistence crops and non-agricultural income. Fink et al. (2014) collected detailed income data from a larger sample from the same District, but without the requirement that they work with Dunavant, find that mean annual household income for smallholder farmers in the District is 4.3 ZMK million (s.d. 5 million).

${ }^{40}$ Equation (3) can be rewritten as

$$
\Pi(N)=\left(\tau \alpha_{0}-\gamma_{0}\right) N-\left(\tau \alpha_{1}+\gamma_{1}\right) N^{2}-\gamma_{2} \times \mathbf{1}(N>0)
$$

where $\tau=\sum_{t=7}^{\bar{T}} \frac{1}{(1+r)^{t}}$. This function is concave in the number of trees as long as $\alpha_{0}>0, \alpha_{1}>0, \gamma_{0}>0, \gamma_{1}>0$, $\gamma_{2}>0$, and $\tau \alpha_{0}-\gamma_{0} \geq 0$.
} 
heterogeneity across farmers. We therefore turn to a quasi-profit function that uses our experimental variation to characterize farmer heterogeneity along two important dimensions of the farmer's profit maximization problem, $\max _{N} \Pi(N)$ : the interior solution and the profit level evaluated at the optimal number of trees.

Quasi-profit function The same interior and corner solutions conditions delivered by (3) are generated by the following quasi-profit function indexed by two random parameters, $T_{i}$ and $F_{i}$ :

$$
\Pi(N)=N-\frac{1}{2 T_{i}} N^{2}-F_{i} \times \mathbf{1}(N>0)
$$

where $T_{i}=\frac{\tau \alpha_{0}-\gamma_{0}}{2\left(\tau \alpha_{1}+\gamma_{1}\right)}$ and $F_{i}=\gamma_{2}+\left(\frac{\left(\tau \alpha_{0}-\gamma_{0}\right)-\left(\tau \alpha_{0}-\gamma_{0}\right)^{2}}{4\left(\tau \alpha_{1}+\gamma_{1}\right)}\right)$. This alternative profit function allows for heterogeneity across farmers in the interior solution (which is equal to $T_{i}$ ) as well as parameter $F_{i}$, which is a scaling parameter that ensures profits in the quasi-profit function coincide with profits in the generic quadratic function when evaluated at the interior solution. The advantage of (4) over (3) is that all random parameters are identified out of the variation induced by our experiment. Because both functions have the same value at the optimal solution, (4) can be used to evaluate welfare under the more general profit function (3).

\section{Introducing a reward for follow-through}

The farmer's objective function when faced with an external reward for follow-through (tree survival above the threshold $\bar{N}$ ) is

$$
\Pi\left(N \mid F_{i}, T_{i}, R_{i}\right)=\left(N-\frac{1}{2 T_{i}} N^{2}\right)+\mathbf{1}(N \geq \bar{N}) R_{i}-\mathbf{1}(N>0) F_{i}
$$

where $R_{i}$ denotes the randomized reward. As we discuss below, the random variation in $R_{i}$ will allow us to identify the conditional distribution of $F_{i}$ given $T_{i}$.

\section{Deterministic survival of trees conditional on effort}

Through out our estimation, we assume that survival of trees is deterministic conditional on farmers' costly effort. As we explain in explain in greater detail in Appendix 3 , this assumption is consistent with a model where probability of survival is a convex continuous function of effort, $e$, up to $\tilde{e}$, where it attains one. Farmers would respond to such probability profile by investing the minimum effort that guarantees survival, $\tilde{e}$, in all trees they choose to plant. ${ }^{41}$ We believe this is a reasonable assumption to make in our context, given that we observe a small bunching of tree survival at 35, which is consistent with perfect targeting of the tree threshold that guarantees receiving the reward (see Appendix figure A.3.1).

\footnotetext{
${ }^{41}$ Except, perhaps, on one of them, as is explained in Appendix 3.
} 
Alternatively, one could assume that effort choices still affect the probability of survival, but no level of effort can guarantee survival of the tree. In Appendix 3 we use Monte Carlo simulations to explore how this alternative assumption would affect farmers decisions and observed outcomes. Given the bunching at 35 trees, we assume that the maximum probability of survival is relatively close to one, as smaller probabilities would eliminate the discontinuity in the distribution. The results from the simulations suggest that introducing stochastic survival conditional on effort does not change farmers' behavior relative to the incentives we provide in any meaningful way. Specifically, the responses of take-up and follow-through decisions to the take-up subsidy and threshold rewards remain approximately of the same magnitude. Appendix table A.3.1 shows the results from the simulation exercise.

\subsection{Dynamics and take-up decision}

As in the conceptual model, we assume the farmer makes adoption-related decisions in two periods: $t=0,1$. The random parameter $F_{i}$ described in the previous section is divided into two orthogonal and additive components: $F_{0 i}$ and $F_{1 i}$, where $F_{0 i}$ is known at all periods and $F_{1 i}$ is known at $t=1$ but not at $t=0$. Given the additivity assumption, the assumption of orthogonality between $F_{0 i}$ and $F_{1 i}$ is relatively innocuous since $F_{0 i}$ can be interpreted as the location shift in the distribution of $F_{1 i}$. I.e., a positive correlation between $F_{0 i}$ and $F_{1 i}$ would be isomorphic to a high variance in $F_{0 i}+\mathbb{E}\left(F_{1 i} \mid F_{0 i}\right)$. In addition, we assume that $T_{i}$ (which corresponds to the interior solution to the maximization problem) is known to the farmer at all times. Given that the random parameter $F_{i}$ governs the level of profits (evaluated at the optimal number of trees), this amounts to assuming that there is uncertainty about the net returns to tree cultivation, while the optimal scale of the technology is known to the farmer at all points in time. The advantage of assuming this particular structure of information is that it allows us to nest a model without uncertainty (i.e., $\operatorname{Var}\left(F_{1 i}\right)=0$ ) that could also generate high take-up and low follow-through within our more general model.

Thus, summarizing, there are two sources of static heterogeneity: the scale of the profit component, $F_{0 i}$, and the interior solution, $T_{i}$. Through a negative correlation in these two random parameters, the model allows for farmers who take-up under a full price to have higher or lower tree survival outcomes than they would under a subsidized price. This is important, since part of the aim of this paper is to investigate the importance of uncertainty in explaining low follow-through decisions after take-up vs. other alternative explanations that rely on static heterogeneity.

At $t=0$, the farmer decides whether or not to pay to take-up the technology. At this point in time, the farmer has partial information about her net benefits from the contract. We assume that

the farmer knows the distribution of $F_{1 i}$ conditional on $F_{0 i}$ and $T_{i}$ at the time she makes her decision to take-up. More precisely, farmers know that $F_{1 i} \sim \operatorname{normal}\left(0, \sigma_{F}^{2}\right)$, such that $F_{i} \sim \operatorname{normal}\left(F_{0 i}, \sigma_{F}^{2}\right)$. Thus, the farmer chooses to take-up if 


$$
\delta \mathbb{E}\left[\max _{N} \Pi\left(N \mid T_{i}, F_{0 i}, F_{1 i}, T_{i}, R_{i}\right) \mid F_{0 i}, T_{i}\right]-c+A_{i} \geq 0
$$

where $c$ is the cost of the seedlings, $A_{i}$ is the randomly determined subsidy, and $\delta$ is the discount factor, which we assume is equal to $0.6{ }^{42}$ The expectation in (6) is taken over the distribution of $F_{1 i}$ conditional on $\left(F_{0 i}, T_{i}\right)$.

\subsection{Identification and estimation}

Identification of the structural model consists of uniquely identifying the joint distribution of unobservables $T_{i}, F_{0 i}$ and $F_{1 i}$. Identification relies on the observed variation in tree survival and take-up decisions across different treatments and a distributional assumption on the random vector $\left(F_{0 i}, F_{1 i}, T_{i}\right)$.

The identification of the joint distribution of $F_{0 i}+F_{1 i}$ (or $F_{i}$ ) and $T_{i}$ can be non-parametrically identified in the subset of the support such that $\bar{N}<T_{i}<50$ and $F_{i}<\frac{1}{2} T_{i}$. To see this, consider the follow-through decision of the subset of the sample for which

$$
\lim _{a \rightarrow \mathcal{A}_{1}} \operatorname{Pr}\left(\mathbb{E}\left[\max _{N} \Pi\left(N \mid T_{i}, F_{0 i}, F_{1 i}, T_{i}, R_{i}\right) \mid F_{0 i}, T_{i}\right] \geq c-a\right)=1,
$$

such that there is no selection on take-up. Within this subset of the sample, we can use the variation in $R$ to identify the joint distribution of $F_{i}, T_{i}$ as well as the marginal distribution of $T_{i}$.

For this group, the probability of cultivating $N^{*}=n>\bar{N}$ trees when $R=r$ can be written as

$$
\operatorname{Pr}\left(N^{*}=n ; R=r\right)=\operatorname{Pr}\left(F_{i}<r+\frac{1}{2} n \mid T_{i}=n\right) \operatorname{Pr}\left(T_{i}=n\right)
$$

Because the left hand side of (7) is empirically observable, increments of $r$ trace out the joint distribution of $F_{i}$ given $T_{i}$.

Since non-parametric identification of the joint distribution of $F_{i}$ and $T_{i}$ occurs only in the subset of the support such that $\bar{N}<T_{i}<50$, additional parametric assumptions are required to fully characterize these distributions. In the empirical estimation we assume that $\ln T_{i}$ and $F_{i}$ are jointly normally distributed, thus the marginal distribution of $T$ is $\log$-normal $\left(\mu_{T}, \sigma_{T}\right)$, while $F_{i}$ is normally distributed with mean $\mu_{F}$ and variance $\sigma_{F}^{2}=\sigma_{F_{0}}^{2}+\sigma_{F_{1}}^{2}$ with the correlation between $F_{i}$ and $T_{i}$ given by $\rho$.

In addition to the additivity and orthogonality assumptions on $F_{0 i}$ and $F_{1 i}$, we need to assume

\footnotetext{
${ }^{42}$ Like Stange (2012), we note that in the context of stochastic dynamic structural models the discount factor is not separately identified from the scale parameter of future period shocks. We collected survey data on time preferences, however, the survey tool used to elicit the discount rate is very coarse and responses are most informative as a relative ranking, so we do not use them directly in our structural estimation. They do, however, inform our choice of 0.6 for the discount factor in the structural estimation. See Footnote 21 for further discussion of this parameter value.
} 
that the distribution of $F_{1 i}$ is iid across farmers in order to separately identify the distribution of $F_{0 i}$ and $F_{1 i} \cdot{ }^{43}$ This new assumption rules out common shocks to farmers. Under these assumptions, the decision to take-up provides independent identification of the known component of $F_{i}, F_{0 i}$, through the variation in $R$ and $A$. This allows us to capture the role of information and uncertainty in the take-up decision and to determine the share of private profit that comes from the option to costlessly exit at $t=1$.

Identification of the distribution of $F_{0 i}$ is obtained from the decision to participate, which is characterized by the inequality in (6). The left side of (6) is a known function of the random variable $F_{0 i}$. Denote this function $h\left(F_{0 i} ; r_{i}\right)$, so we can rewrite $(6)$ as

$$
h\left(F_{0 i} ; R_{i}=r_{i}\right) \geq c-a_{j}
$$

The right side of (8) can take one of four known values, $c-a_{j}$ for $j=1, \ldots, 4$, and is randomly determined by the research design. The left hand side of (8) is known up to $F_{0 i}$ and varies across individuals according to the known cost determinant, $r_{i}$. Provided that $h\left(F_{0 i} ; r_{i}\right)$ is invertible, ${ }^{44}$ we can identify the distribution of $F_{0 i}$, from the random variation in $a_{j}$ and $r_{i}$ :

$$
\operatorname{Pr}\left(F_{0 i} \leq h^{-1}\left(c-a_{j}, r_{i}\right) \mid \mu_{F}, \sigma_{F}^{2}, \mu_{T}, \sigma_{T}, \rho\right)=\operatorname{Pr}\left(\operatorname{Part}_{i} \mid A_{i}=a_{j}, R_{i}=r_{i}\right)
$$

Note that in (9), parameters $\mu_{F}, \sigma_{F}^{2}, \mu_{T}, \sigma_{T}$, and $\rho$ can be treated as known since they are identified from tree survival as described above. However, the random variation in $R_{i}$ and $A_{i}$ allows us to identify $\mu_{F}$ in (9) from the participation decision. We use this feature of our research design to explore whether farmers have correct beliefs on $\mathbb{E}\left(F_{i}\right)$ at $t=0$, and in a model variant we allow for a mean shift in $\mu_{F}$, which would be consistent with an unexpected common shock to all farmers. This variant of the model partially relaxes the assumption of independence of shocks across farmers. However, it is somewhat limited in that its unexpected nature means it does not affect the option value of the contract. A complete relaxation of this assumption, which would allow for free patterns of known correlation in shocks to farmers' costs, is not possible given the limited time horizon in our data.

\section{Estimation}

We estimate the model using simulated maximum likelihood. The log-likelihood function is over observations of the number of planted trees, $N=0, \ldots, 50$, and the participation decision, $D P=0,1$. The sample includes the 1314 farmers who made a take-up decision. Because there are no trees planted whenever the individual chooses not to participate, the support of this bivariate vector is

\footnotetext{
${ }^{43}$ This assumption is also present in Fafchamps (1993), and is necessary for maximum likelihood estimation. We partially relax this assumption in the mean shift model (see below).

${ }^{44}$ It can be shown that there exists some $\bar{f}$ such that $h\left(F_{0 i} ; r_{i}\right)$ is strictly monotonically decreasing on $(-\infty, \bar{f})$.
} 
given by the $52(D P, N)$ pairs: $(0,0),(1,0),(1,1),(1,2), \ldots,(1,50)$.

$$
\begin{aligned}
l(\xi ; D P, N) & = \\
& \sum_{i=1}^{M}\left\{\left(1-D P_{i}\right) \ln \left(1-\pi_{P, i}\right)+D P_{i} \ln \left(\pi_{P, i}\right)+D P_{i} \sum_{j=0}^{50} \mathbf{1}\left(N_{i}=j\right) \ln \operatorname{Pr}(N=j)\right\}
\end{aligned}
$$

where $\xi=\left(\mu_{F}, \sigma_{F_{0}}^{2}, \sigma_{F_{1}}^{2}, b\right)$.

We use numerical methods to minimize the negative of the simulated log-likelihood. For each likelihood evaluation, we use 500 draws of $\left(T_{i}, F_{0 i}, F_{1 i}\right)$. Also within each likelihood evaluation and for each draw of $\left(T_{i}, F_{0 i}, F_{1 i}\right)$, the expectation in the right hand side of equation (6) is numerically computed using 100 draws of $\left(T_{i}, F_{1 i}\right)$ conditional on the draw of $F_{0 i} \cdot{ }^{45}$ Standard errors for the estimated parameters are obtained as the inverse of the inner product of the simulated scores. ${ }^{46}$

\section{Structural Estimates and Simulation Results}

In this section, we describe the structural estimates and carry out a number of counterfactual simulations.

\subsection{Structural Estimates and Model Fit}

Table 3 shows the point estimates for the main parameters described in Section 5.3. ${ }^{47}$ Panel A shows the estimates of our baseline model, which assumes that farmers' expectations about the $F$ are correct and consistent over time. Panel B shows the results of allowing for an unexpected common shock to all farmers at $t=1$ (a mean shifter). As discussed in Section 5.3, this alternative

\footnotetext{
${ }^{45}$ Simulated methods often result in stepwise objective functions which work poorly with gradient-based numerical optimization algorithms. To facilitate the numerical optimization, we "smooth" the objective function by computing the multilogit formula for each decision over participation and the number of trees. We assume a relatively small variance parameter of the logistic error term: 0.5. However, we experiment with different values for this parameter. We find that smoothing does not significantly affect the point estimates and does improve substantially the curvature of our objective function. A further discussion of the estimation algorithm can be found in Appendix A.2.

${ }^{46}$ See Appendix A.2 for a more detailed description of our standard error calculation.

${ }^{47}$ There are two remaining parameters that are omitted from Table 3 but discussed in Appendix A.2 for the sake of brevity: these are the surprise treatment parameter, $\alpha_{S}$, and the monitoring treatment parameter, $\alpha_{m}$. Recall that farmers in the surprise reward treatment made a take-up decision before learning their reward. We model this aspect of the design by assuming individuals expect a threshold reward of 0 when their participation decision is made, but incorporate the reward value they draw in their follow-through decision. Because our reduced form results show that individuals in the surprise treatment had higher participation rates than those individuals who drew a reward of zero ZMK, we allowed the surprise reward treatment to have an independent effect on the participation decision. The structural estimates suggest that the boost to participation is equivalent to offering them between 92 and 54 ZMK (in the model with a mean shifter). Appendix A.2 describes these results in more detail.

In all models, we allow the regular visits to collect data on program implementation that were administered to one-fifth of farmers to independently affect the tree survival decision (but not the participation decision). The estimated parameter is -238.40 (s.e. 73.887) in Panel A and -229.53 (s.e. 74.444) in Panel B. In other words, regular monitoring visits appears to be reducing the fixed costs of tree cultivation, which is consistent with the positive effect of monitoring on tree survival that we find in the reduced form results.
} 
model partially relaxes the assumption of independence in shocks across farmers. Because point estimates are somewhat hard to interpret (e.g. the $\mu_{T}$ and $\sigma_{T}$ parameters do not correspond to the mean and standard deviation of the log-normally distributed parameter $T$ ), we convert the estimated parameters into more easily interpretable outcomes using simulation. ${ }^{48}$ The estimated joint distribution of $T$ and $F$ shown in Panel A is such that the mean ex-post privately optimal number of trees is 8.46 (s.d. 14.64), with about 59 percent of farmers choosing to plant no trees. ${ }^{49}$

This joint distribution also implies that the average ex-post private profit from the optimal number of trees is 108.39 thousand ZMK. However, ex-post private profits vary widely across farmers: their s.d. is 185.47. Importantly, the model estimates that about 39 percent of the variance in ex-post profits is due to new information that emerges after the take-up decision is made.

The variance of shocks is partially identified out of the difference in the variances of expected profits at the time the take-up and ex-post profits at the time the follow-through decision is made and partially identified out of its non-linear effect on the mean level of the expected profits at the time of take-up. ${ }^{50}$ The presence of common shocks will generate a tug-of-war between these two sources of identification, as the expected value of the profits will pull the variance of shocks parameter, $\sigma_{F 1}$, up while the ex-post variance in profits will not reflect the variance of common shocks and thus will pull $\sigma_{F 1}$ down. Our mean shifter model helps us explore the importance of the bias in $\sigma_{F 1}$ generated by the presence of common shocks, as it allows for the mean level of profits to be different at the time of take-up and at the time the follow-through decision is made.

The corresponding results from the mean shifter model are presented in Panel B of Table 3. The results are consistent with the presence of common shocks, but also suggest the share of variance attributed to them is relatively small: the mean shifter parameter is positive, which reflects the higher mean level of expected profits; while the idiosyncratic shock variance parameter, $\sigma_{F 1}$, falls moderately from 211.42 to 193.05 , which is consistent with a positive bias in our baseline model stemming from the presence of common shocks. ${ }^{51}$ The remaining results are qualitatively similar. The mean number of privately optimal trees is 7.67 (s.d. 14.00) and the mean ex post private profit is 90.46 (s.d. 163.73). The share of the variance in ex-post profits attributed to idiosyncratic shocks remains high: 40 percent.

We now turn to the interpretation of the parameters that govern the distribution of known (at

\footnotetext{
${ }^{48}$ The point estimates in Table 3 can be used to simulate farmer's draws of $F$ and $T$. These draws can then be used to compute optimal tree cultivating decisions that account for interior and corner solutions to the optimization problem. The optimal solutions can then be plugged back into the profit function to compute maximized profit. The statistics presented below correspond to means and variances from 10,000 simulated draws.

${ }^{49}$ These statistics assume that they can plant a maximum of 50 trees. Although we allow for the distribution of $T$ to be unbounded, we chose to present statistics of the bounded distribution because we fit the econometric model using only this range of outcomes. According to our estimates, about 6 percent of the farmers would choose a private optimum of 50 or more trees.

${ }^{50}$ Recall that a higher variance in shocks results in a larger option value for the contract.

${ }^{51}$ Unfortunately, we cannot calculate the share of the variance attributed to common shocks using model estimates as we are not explicitly modeling random common shocks with a known distribution at the time of take-up.
} 
the time of take-up) sources of heterogeneity across farmers. We estimate a high positive correlation between $F$ and $T, \rho=0.81$ ( $\rho=0.83$ in the mean shifter model).$^{52}$ Because $F$ enters negatively in the profit function, this translates into a negative correlation between the privately optimal number of trees and the level of profits. This negative correlation generates low, but strictly positive, follow-through rates (as in low numbers of trees planted) among farmers whose expected value from the contract is high and thus take-up under a high price of the contract. In other words, the static heterogeneity identified by the model contributes to undermining the effect of high prices at take-up on positive (high follow-through) self-selection of farmers.

Because $F$ and $T$ are reduced form parameters (see Subsection 5.1), the positive correlation between them could stem from two sources: a positive correlation between farmers' fixed costs and farmers interior solution to the maximization problem (a component of the reduced form random parameter, $F$, is the fixed cost of the generic quadratic profit function), or a high mean and high variance in the linear term of net marginal returns (the term $\tau \alpha_{0}-\gamma_{0}$ in the reduced form expression for $T$ and $F$ ), which enters linearly in $T$ and non-linearly in $F$, and in high ranges may generate a negative relationship between them. Our model predicts well some of the simple observations drawn from the data in the reduced form section 4. For example, our baseline model predicts that 1104 farmers (1112 under the mean shifter model), out of a total of 1314, will take-up; our data show 1092 participants. Our model also predicts that 173 out of the 963 farmers that faced a strictly positive take-up cost (i.e. a subsidy less than 12,000 ZMK) will choose to cultivate zero trees (180 in the mean shift model), while the observed number of farmers in this category is 112 . That is, the dynamics in our model replicate the observation that seems at odds with rationality in a static framework: some farmers who purchase the trees choose not to cultivate them. In this sense, our result parallels the result by Fafchamps (1993) in that individuals make costly choices to maximize future flexibility.

Next, we further examine the model fit by comparing the reduced form treatment effects using simulated outcomes from the estimated model and the observed data. Most of the magnitudes and signs between the treatments and outcomes are well matched by our model estimates. Panel A of Table 4 shows results with the observed data, while Panels $\mathrm{B}$ and $\mathrm{C}$ show the corresponding simulations using the estimates from Table 3. Columns 1-4 estimate the effect of a thousand ZMK increase in the subsidy on take-up and follow-through outcomes. Columns 5-8 repeat the regressions with the reward (in '000 ZMK) on the righthand side. The effect of the subsidy and the reward on take-up (columns 1 and 5) show very similar coefficients for the observed and simulated datasets. The estimates for whether the farmer reached the 35-tree threshold (columns 2 and 4, conditional on take-up) are also similar across the observed and simulated data, with slightly higher estimated effects of the reward on reaching the threshold in the simulated data.

\footnotetext{
${ }^{52} F_{1}$ is assumed to be orthogonal to $F_{0}$ and $T$. Thus, the correlation between $F$ and $T$ stems solely from the correlation between $F_{0}$ (the known component of $F$ ) and $T$.
} 
There are, however, some discrepancies between what our model predicts and the observed data. Columns 3 and 7 show the effect of the take-up subsidy and reward on the number of surviving trees, excluding zeros (which are shown in columns 4 and 8). Interestingly, the sign of the coefficient on the subsidy is different between the observed and simulated data, though standard errors are relatively large. The effect of the reward on the number of trees (column 7) is larger in the simulated data, consistent with the effects on reaching the 35-tree threshold. Finally, we see evidence that the takeup subsidy selects for farmers more likely to keep zero trees alive (column 4) in the simulated but not in the observed data, indicating some selection effect on abandoning the technology altogether in the simulated data only. The effect of the reward on zero tree survival is the same in the observed and simulated data.

Using simulations, we explored whether some of the discrepancies between our estimated model and the data stem from the assumption of deterministic survival of the trees conditional on effort. To do this, we take the parameter estimates as given (we use the estimates from the mean shifter model) and incorporate a binomial and a beta binomial distribution to the survival outcomes of trees under a couple of different parameter values. ${ }^{53}$ We find little to no improvement when stochasticity is introduced into the tree survival outcomes: the simulations that incorporate stochastic survival of trees show no improvements on matching the observed relationships between the take-up subsidy and the positive number of trees or the take-up subsidy and choosing zero trees. The beta binomial distribution shows little improvement at matching the relationship between the take-up subsidy and the positive number of trees as well as the choice of zero trees; although it does so at the expense of worsening the fit for the relationship between the reward and take-up.The results from these simulations are further discussed in Appendix A.3 .

\subsection{The effect of uncertainty on farmer profits and program outcomes}

We use estimates from the structural model to perform counterfactual simulations of farmer profits and program outcomes (take-up and tree survival) under different levels of uncertainty. For these analyses, we use the results from the model that allows a more flexible specification of $F_{i}$ with the mean-shifter parameter, such that both the mean and the standard deviation of $F_{i}$ may vary over time (Panel B in Table 3). This version of the model offers the best approximation of our observed take-up and tree survival results. In the simulated results below, we set the mean shifter for $t=1, \mu_{F_{s}}$, equal to zero, so that we can equate the expected benefits with the true average discounted benefits from the program in the welfare evaluations. ${ }^{54}$ Results from using our baseline model estimates instead are qualitatively similar.

\footnotetext{
${ }^{53}$ We chose not to reestimate the structural parameters under the alternative assumption for tree survival, given that our simulations suggested that stochastic survival of trees was unlikely to improve the fit of the model, and that estimation of the model is very time consuming.

${ }^{54}$ This treatment of the mean-shifter parameter is consistent with the common-shock interpretation of this parameter.
} 


\section{Farmer profits}

We begin by examining the effect of uncertainty on the average per-farmer expected private profit (right hand side of inequality 6) implied by the empirical model.

In order to do so, we simulate the value of the expected profit for each farmer at different values of $\sigma_{F 1}$. The relationship between the mean expected profit and $\sigma_{F 1}$ corresponds to the solid black curves in Figure 3. Panel A shows the relationship for a reward of zero and Panel B for the largest reward offered (150 thousand ZMK). Both are shown at a full subsidy, so that take-up is 100 percent. The first takeaway from this figure is that uncertainty increases the expected profit, for both low and high rewards. This result is analogous to the theoretical result discussed in Proposition 4: the option value from the contract increases with uncertainty and thus drives a positive relationship between the expected profit and uncertainty. The option value, as defined in 2 , is shown by the dashed lines in Figure 3 for different values of the reward. The option value is always non-negative (as farmers could only do better with more information, but never worse), and is also the only component of the expected private profit that varies with uncertainty.

Recall that this result stems from the asymmetric response of the expected profit to positive and negative shocks: If the realization of the random component of the profit from follow-through is high (low $F_{1}$ ), then the farmer responds by securing that profit through positive tree tree survival. However, if the realization of the random component of the profit drives it below zero, the farmer will respond by not cultivating any trees at all (effectively bounding the profit realizations at zero). This optimizing behavior turns the high variance of the shocks into an asset of the contract, which in turn results in higher take-up.

The positive relationship between expected private profit and uncertainty has an important implication for take-up decisions: more farmers are ex ante attracted to the contract under higher uncertainty, despite the fact that its ex post expected value remains unchanged. Note that a high enough level of uncertainty may result in an expected profit that exceeds the take-up cost even under low subsidies. Hence, the ability of subsidies to "tease out" those who will be more likely to comply with the tree survival goal decreases with uncertainty. This can be observed more directly when looking at take-up and follow-through outcomes as a function of uncertainty, which we turn to next.

\section{Program outcomes}

Figure 4 plots average take-up at low and high subsidies (dashed and solid lines) and low (Panel A) and high (Panel B) rewards as a function of uncertainty. Panels C and D show the share of individuals who reach the 35-tree goal conditional on take-up for the same combinations of subsidies and rewards. Figure 5 shows the effects of uncertainty on the average number of trees for different values of the subsidy $(A)$ and reward $(R)$. Panels A and $\mathrm{B}$ show the average tree survival, 
unconditional on take-up (non-participants have zero surviving trees). Panels $\mathrm{C}$ and $\mathrm{D}$ show average tree survival conditional on take up. Because take-up is 100 percent with a full subsidy $(\mathrm{A}=12)$, the solid lines in Panels C and D coincide with the solid lines in the Panels A and B, respectively.

First note that the average number of trees conditional on take-up is boosted by a high take-up cost (low $A$ ) when uncertainty is low (the boost corresponds to the difference between the two lines in Panels $\mathrm{C}$ and $\mathrm{D}$ ). This boost is what we refer to as the selection effect of price. This result from the model, the existence of a selection effect for low levels of uncertainty, is analogous to Propositions 1 in our conceptual model (Section 2). For the level of uncertainty identified from our data, a value of $\sigma_{F 1}$ of 195, the boost from high take-up cost to tree survival is modest: less than 5 trees; and it continues falling as uncertainty further increases. The reduction in the selection effect as uncertainty increases is analogous to Proposition 3 in our conceptual model.

Second, uncertainty lowers follow-through conditional on take-up whenever the price for takeup is high. This is illustrated by the downward slope of the dashed line with circles in Panels $\mathrm{C}$ and $\mathrm{D}$ in figure 5. This effect is driven by the selection effect of the positive price fading away as uncertainty increases: as can be seen from Panels A and B in figure 4, take-up converges to 100 percent as uncertainty increases, making the pool of takers ever more similar to the overall pool. This is broadly consistent with Proposition 2 from our conceptual model, although the analogous result in this richer model is qualified by an additional competing effect: the variance of shocks can have a positive or negative effect in the number of farmers that choose zero trees depending on whether the sign of this corner solution threshold is to the right or to the left of the mean of $F$. We call this effect the corner solution effect. Whenever the reward for the 35 tree goal is at $150 \mathrm{ZMK}$, the threshold is positive. Whenever the reward for the 35 tree goal is zero, the threshold is negative. Thus, when the reward is zero, we see that the unconditional average number of trees increases with uncertainty (both lines in Panel $\mathrm{A}$ and the solid line in Panel $\mathrm{C}$ increase with $\sigma_{F_{1}}$ ). Whereas the opposite is true when the reward for trees is 150 ZMK (both lines in Panel A and the solid line in Panel D fall with $\left.\sigma_{F_{1}}\right){ }^{55}$ Thus, in this richer model, the effect of uncertainty on follow-through conditional on take-up carries both effects: the selection effect, which lowers follow-through; and the corner solution effect, which has an ambiguous effect on follow-through. In our context, the selection effect dominates the corner solution effect, and thus follow-through falls with uncertainty conditional on take-up.

The fact that average follow-through conditional on take-up falls with uncertainty has important

\footnotetext{
${ }^{55}$ This effect holds whenever the distribution of shocks is continuous and symmetric around the mean. To see this, denote the standard normal cdf as $\Phi($.$) and the threshold along the support of F$ above which the private profit associated with the interior solution is negative as $\tilde{F}$. The probability of choosing to plant zero trees takes the form $1-\Phi\left(\frac{\tilde{F}-\mu_{F}}{\sigma_{F_{0}}+\sigma_{F_{1}}}\right)$. Note that the derivative of this probability with respect to $\sigma_{F_{1}}$ has the same sign as the numerator of the argument of $\Phi($.$) . When R=0, \tilde{F}=\frac{1}{2} T_{i}$. Given that $\mu_{F}$ is above 100 and the mode of $T_{i}$ is 8.9 , the numerator tends to be negative. However, when $R=150$ and $N^{*} \geq 35, \tilde{F}=N^{*}-\frac{1}{2 T_{i}} N^{* 2}+150$; and, thus, the numerator tends to be positive.
} 
implications for technologies whose benefits kick in above a certain "usage" level: under low levels of uncertainty about implementation costs, a high cost of take-up will help select those individuals who are likely to engage in a more intensive usage of the technology.

The third observation is that boosts to take-up from increasing the subsidy may trump some of the selection effects. This is most clearly seen by comparing unconditional tree survival (Panels $\mathrm{A}$ and $\mathrm{B}$ of Figure 5) with tree survival conditional on take-up, which excludes the take-up effect (Panels C and D). The boost associated with the selection effect observed at low levels of uncertainty in Panels $\mathrm{C}$ and $\mathrm{D}$ is more than offset by the take-up effect: many more farmers take-up when subsidies are high (see Panels A and B in Figure 4). The two counteracting effects lead to similar average tree survival across subsidy levels, unconditional on take-up (Panels A and B). Hence, for technologies whose benefits kick in with total follow-through (whether or not follow-through is spread about few or many adopters), subsidies may increase the benefits of adoption. Note, however, that uncertainty removes the take-up advantage of high subsidies, as take-up increases with uncertainty for all subsidy levels (e.g. doubling uncertainty relative to the level observed in our setting increases take-up from 85 to 97.5 percent at the average take-up subsidy in our setting).

The last observation from both Figures 5 and 4 is that under high uncertainty, a reward conditional on follow-through is more effective at inducing higher levels of follow-through than a subsidy. This can be appreciated when comparing the lines with higher $R$ with the lines with lower $R$. We also note that the combination of low take-up subsidy and high threshold reward works best to maximize the share of individuals whose follow-through falls above the 35-tree threshold conditional on take-up, but this combination of incentives works best under low uncertainty (Panel D of figure 4). Even with this combination of incentives, uncertainty can bring down the number of farmers that reach the 35-tree threshold. Taking the level of uncertainty we identify from our data as a baseline, a standard deviation in the unknown part of the cost $\left(\sigma_{F_{1}}\right)$ that is twice as large would bring down the share of farmers that attain 35 trees or more from 65.5 to 54.7 percent. Conversely, halving the standard deviation would increase the share of individuals who reach 35 trees or more to 80 percent (Panel D of figure 4). ${ }^{56}$

\section{Discussion and interpretation}

Our model and results are consistent with several interpretations of intertemporal adoption decisions and the nature of the uncertainty that farmers face. Our default interpretation is one of idiosyncratic and common shocks to the opportunity cost of follow-through with the technology,

\footnotetext{
${ }^{56}$ We can also perform these simulations with the randomized treatment levels we used in our experiment. Relative to the level of uncertainty we identify from our data, which results in 49.6 percent of farmers reaching the 35 -tree goal, doubling uncertainty lowers this share of farmers to 39.96 percent, while halving it increases follow-through to 67.12 percent, conditional on take-up. In the absence of uncertainty $\left(\sigma_{F 1}=0\right), 88.7$ percent of farmers who take-up reach the follow-through threshold.
} 
with idiosyncratic shocks playing a relatively more important role. However, results would look similar if instead farmers learn about the technology between the time of the take-up and followthrough decisions. A third explanation for the intertemporal decisions we observe, which would violate our identifying assumptions, is that farmers have time inconsistent preferences. We describe supplementary evidence on each of these explanations in this section.

\subsection{Common vs. idiosyncratic shocks}

In our surveys and in other developing country micro data, farmers frequently refer to shocks as a primary determinant of agricultural outcomes. The first version of our model treats the ex post variance in profits across farmers as the sum of the variances of the known and unknown components of the private profit, and therefore allows for idiosyncratic but not common shocks. This restriction on the distribution of the information revealed at time 1 is relaxed in our second version of the model, where we allow for an unexpected mean shift on the distribution of private profit at time 1. The data indicate that the mean shift, which could be interpreted as an unexpected common transitory shock or as homogenous learning (see below), is consistent with a common increase in costs after take-up. The estimated mean shift is small in magnitude relative to the variance (see Table 3). We interpret this estimate as evidence of common shocks but of limited importance.

The variation in our data does not allow us to identify other types of common shocks: namely, shocks whose distribution is known at time 0 , or that are correlated across subsets of farmers (as opposed to all). Therefore, to assess the validity of our identifying assumptions, we consider two additional sources of information about the importance of common and idiosyncratic shocks: household self-reports from the baseline and endline data and the existing literature on agricultural productivity in rural Sub-Saharan Africa.

First, two of the most frequently discussed common shocks are weather and prices. In our setting, the primary source of price risk is from cotton, which experienced a very negative shock in the year of study. At baseline, 97 percent of respondents who forecasted a minimum cotton price for the coming year that exceeded the realized price. Close to 80 percent of the households in our study grew cotton in the contract year, and were therefore affected by the price shock. To the extent that the negative shock to cotton prices was very unlikely from the farmer's stand point, the mean shifter model is likely to capture its effects on farmers' decisions and to reduce the bias in our estimates of the variance of idiosyncratic shocks. Unlike cotton prices, rainfall was fairly typical during the year of the contract, according to local agronomists. Note, however, that to the extent that there are common shocks (such as crop prices and rainfall) whose variance is known and thus are incorporated in the take-up decision, our estimates for the variance of idiosyncratic shocks will continue to be biased upwards even in the mean shifter model.

According to our baseline data, idiosyncratic shocks seem to be an important concern for farmers. When participants were asked about the greatest challenges facing their households, respondents 
describe issues unrelated to correlated shocks. Two-thirds of respondents list health problems as their greatest challenge. At endline, almost 50 percent of households report losing cattle or livestock to death or theft during the past year and 10 percent of households reporting the death or marriage of a working age member.

Second, a growing literature documents large negative effects of household illness on labor supply and agricultural productivity in the region of study (e.g., Fink and Masiye 2012) and on consumption more broadly (for example, Gertler and Gruber 2002). These findings are consistent with a larger literature that documents, in most cases, a disproportionate share of income risk from idiosyncratic factors in rural developing country settings (summarized in Dercon 2002). Thus, we conclude that while common shocks are potentially an important source of uncertainty in agriculture, the fact that our model focuses on idiosyncratic shocks appears reasonable in this context.

\subsection{Learning}

As discussed throughout the paper, the theoretical and empirical models are similar, from an ex ante perspective, if the information that arrives between $t=0$ and $t=1$ is in the form of learning or in the form of a shock to opportunity cost, provided that both types of new information are independent across farmers. In addition, to the extent that non-idiosyncratic learning shocks are common across all farmers and unexpected, the mean shifter model could account for learning. Interpreted this way, the positive mean shift estimate is consistent with farmers systematically underestimating the costs of follow-through at the time of take-up. That said, the estimated magnitude of the mean shift parameter is small, suggesting relatively little systematic updating across all farmers. Learning shocks that are independent across farmers and whose distribution is known by the farmers ex ante would show up in the variance of $F_{1}$. Thus, we cannot distinguish between permanent (learning) and transitory shocks to the opportunity costs of planting the trees.

The potential for learning about the value of the technology during the first year of tree production is somewhat limited given that tree survival benefits are not realized until several years after the end of the study, and planting and caring for trees resembles activities that farmers undertake regularly. Thus, if learning occurs, it is likely related to the opportunity costs of cultivating the trees, rather than the benefits. We use survey data to explore the extent to which knowledge of the technology changes over the course of the year-long contract.

Our most reliable survey measure of knowledge about the cost of cultivating the trees is the number of risks to tree survival that the farmer is able to list. ${ }^{57}$ This measure has a number of weaknesses: first, differences in stated risks may be driven by heterogeneity in risks across farmers rather than differences in knowledge, and second, because the risks were discussed at training, the question may offer a better measure of memory than of knowledge. Out of four major risks to the trees (see Section 3.3), farmers list an average of 1.64 risks at baseline and 1.75 at endline one year

\footnotetext{
${ }^{57}$ Specifically, the question asks: "What are the risks to the tree once it is in the field? List all you can think of."
} 
later. Farmers who took up the contract show a larger increase in knowledge than those who did not take-up. This is driven both by actual increases in knowledge by some adopters and high rates of forgetting by non-adopters. Appendix table A.4.6 shows the correlations between tree survival outcomes and survey measures of knowledge and learning. Conditional on take-up, tree survival is higher among those who knew more about the technology at baseline, measured either by the number of risks to tree survival that they were able to name (column 1) or by their prior adoption of the tree (column 2). We proxy learning about the technology by changes in the number of risks listed at endline versus baseline. Farmers who increased the number of risks listed actually cultivated more trees, which suggests that learning about additional costs does not deter follow-through (column 1). While having a farmer in the group who had adopted the technology before the program, and may be a source of information about tree cultivation, is positively correlated with additional trees, the relationship is imprecisely estimated. These correlations should not be interpreted as causal, but do suggest that a modest amount of the information that arrives after take-up may be in the form of learning about the technology. Including all four knowledge and learning measures in the regression (column 4) increases the R-squared from 0.0951 to 0.1460 .

\subsection{Procrastination}

An alternative explanation for the observed pattern of high take-up and low compliance is procrastination or hyperbolic time preferences. Sustained effort choices are frequently associated with time inconsistent behavior, in which the individuals initially takes up, intending to follow-through. But when the time comes to act, costs loom larger (or benefits smaller) than anticipated at the time of initial take-up decision. Mahajan and Tarozzi (2011) document time inconsistent technology adoption for insecticide treated bednets in India, with low rates of net re-treatment.

We examine evidence for procrastination or hyperbolic time preferences by constructing two measures of procrastination from the survey data. The first of these relies on a series of baseline survey questions about the respondent's tendency to spend money quickly or delay purchases or actions. These questions are combined into a binary measure of procrastination, which is likely to miss naive procrastinators. ${ }^{58}$ As part of the endline survey, a series of questions about procrastination in other activities, including paying school fees, purchasing agricultural inputs and milling maize were added to the survey. These are combined into a second binary measure, which is more likely to capture naive procrastinators.

We begin by examining whether these measures of procrastination are correlated with contract take-up or tree survival conditional on take-up, controlling for other characteristics. They are not. We next investigate the insight that farmers prone to procrastination may be differentially

\footnotetext{
${ }^{58}$ Specifically, the baseline questions prompted (1) If I get money, I tend to spend it too quickly, (2) I often change my mind and do not follow-through with my original intention and (3) I tend to postpone activities until later. All responses were on a four point Likert item from strongly disagree to strongly agree. A binary measure was constructed to equal one if the respondent agreed or strongly agreed with any of the statements.
} 
sensitive to a contract structure that requires them to pay more upfront for inputs if the potential rewards arrive only after a year of effort. We regress take-up on an interaction of each of the two procrastination measures and the subsidy level. For the self-described procrastinators, there is a weakly greater likelihood of take-up at higher subsidy levels. However, the interaction is insignificant with the measure more likely to capture naive procrastinators. These results are summarized in Appendix table A.4.7, and suggest a relatively minor role for procrastination in driving take-up or follow-through outcomes.

\section{Conclusion}

This paper shows that uncertainty can play an important role in the adoption of technologies that require costly effort over time. The literature on technology adoption so far has emphasized liquidity constraints and learning as potential reasons why take-up subsidies need not lead to too much takeup by adopters with a low likelihood of following through with the technology. We provide a broad framework for adoption decisions that allows for time-fixed and time-varying heterogeneity as well as multiple dimensions of static heterogeneity across potential adopters. Using a conceptual model, we show that uncertainty in the opportunity cost of adoption can increase take-up rates at the cost of reducing average follow-through rates. Our conceptual model allows for unknown but permanent components of opportunity costs of adoption, such as learning, but may also include transient shocks such as illness in the family. We show that the presence of uncertainty at the time of take-up may explain why high prices are unable to screen for high-follow through types at the time of take-up.

Findings from a field experiment show evidence that is consistent with the presence of uncertainty in agricultural technology adoption. In Zambia, farmers decide whether to take-up a nitrogen fixing tree under considerable uncertainty about the benefits and costs of following through to keep the tree alive. The study introduces exogenous variation into the initial subsidy for take-up and random variation in the reward associated with following through for the first year. We find that, although farmers are responsive to both subsidies for take-up and rewards for follow-through, lower subsidies (higher prices) do not help screen individuals who are more likely to follow-through. We also find that 35 percent of farmers who paid a positive price for take-up end up with no trees after a year. These observations are consistent with the arrival of new information between the take-up and follow-through decisions. Like Fafchamps (1993), we show that behavior that seems at odds with rationality under a static framework is consistent with a dynamic model of rational decision making under uncertainty where individuals make costly choices to maximize future flexibility.

The experimental variation is used to identify a structural model of intertemporal decision

making under uncertainty, which explains our field results and quantifies the uncertainty that the farmers face at the time of take-up. The structural model also helps distinguish between static and time-varying sources of heterogeneity that may explain the absence of screening effects of prices. 
We find that, in our setup, both static and time-varying heterogeneity reduce the screening effect of the take-up price. Reducing uncertainty to a half would increase the number of farmers that reach tree survival threshold by 18 percentage points (36 percent).

Like all empirical case studies, our data are specific to our setting. However, the combination of the experimental data with a structural model allows us to simulate adoption outcomes under different levels of uncertainty. Our results are consistent with several different interpretations of what changes for farmers between the time of the take-up and the follow-through decisions. First, farmers may experience shocks, such as an illness in the household or the arrival of agricultural pests, that affect the opportunity cost of following through with the technology. Second, farmers may acquire additional information about the net costs of tree cultivation after take-up through learning by doing or learning from peers. Finally, farmers may exhibit time inconsistency and choose to procrastinate after take-up. From an ex ante modeling perspective, our general framework is agnostic about which explanation is correct. Though we cannot distinguish among them using our experimental design, supplementary evidence suggests that idiosyncratic shocks are important in our setting and that learning opportunities, while present, are minimal.

Our study is an example of how experimental variation can be used to identify dynamic structural models. The use of experimental variation in treatments at two different points in time offers an alternative to a panel data structure, since statistically independent samples are exposed to different treatment combinations. To our knowledge, this is the first paper to introduce experimental variation in order to satisfy the exclusion restrictions needed for sequential identification. One caveat of our basic identification strategy is that it relies on shocks being independent across farmers. Therefore, a variant of our model allows for a uniform common shock to farmers, provided that it is completely unanticipated (i.e. the subjective probability assigned by farmers is zero).

From a policy standpoint, uncertainty has the effect of lowering adoption outcomes per dollar of subsidy invested, while increasing the expected private profits to the adopter, because the downside risk of take-up is bounded at zero. To the extent that subsidies rely on public funds, an increase in uncertainty represents an ex ante transfer from the public to the private domain, driven entirely by adopter's ability to re-optimize follow-through once new information becomes available. While stronger contracts that would force adopters to follow-through once they take-up a subsidized technology would address the problem of high take-up (and subsidization) coupled with low follow-through, they would do so at a clear cost to the adopter. Future research to explore more innovative solutions to encouraging both take-up and follow-through in the presence of uncertainty offers a promising direction for both environmental and development policies. For example, cheaper monitoring solutions that facilitate subsidies (rewards) for follow-through outcomes are shown to have positive effects on both take-up and follow-through in our setting. 


\section{References}

Akinnifesi, F. K., O. Ajayi, Sileshi, P. W. Chirwa, And J. Chianu (2010): "Fertiliser trees for sustainable food security in the maize-based production systems of East and Southern Africa: A review," Agronomy for Sustainable Development, 30, 615-629.

Ansar, J. And R. Sparks (2009): "The experience curve, option value, and the energy paradox," Energy Policy, 37, 1012-1020.

Arrow, K. J. AND A. C. Fisher (1974): "Environmental preservation, uncertainty, and irreversibility," Quarterly Journal of Economics, 88, 312-319.

Ashraf, N., O. Bandiera, And B. K. JaCK (2014): "No margin, no mission? A field experiment on incentives for public service delivery," Journal of Public Economics, 120, 1-17.

Ashraf, N., J. Berry, And J. M. Shapiro (2010): "Can higher prices stimulate product use? Evidence from a field experiment in Zambia," American Economic Review, 100, 2383-2413.

Ashraf, N., B. K. JaCK, And E. KameniCA (2013): "Information and subsidies: Complements or substitutes?" Journal of Economic Behavior \& Organization, 88, 133-139.

Barnes, R. And C. FAgG (2003): "Faidherbia albida: Monograph and annotated bibliography," .

Beaman, L., D. Karlan, B. Thuysbaert, and C. Udry (2014): "Self-Selection into Credit Markets: Evidence from Agriculture in Mali," Working Paper.

Berry, J., G. Fischer, and R. P. Guiteras (2012): "Eliciting and utilizing willingness to pay: Evidence from field trials in Northern Ghana," Working Paper.

Bontems, P. And A. Thomas (2000): "Information value and risk premium in agricultural production: the case of split nitrogen application for corn," American Journal of Agricultural Economics, $82,59-70$.

Brown, S. (1997): Estimating biomass and biomass change of tropical forests: a primer, vol. 134, Food \& Agriculture Org.

Bruhn, M. And D. McKenzie (2009): "In pursuit of balance: Randomization in practice in development field experiments," American Economic Journal: Applied Economics, 1, 200-232.

Bryan, G., S. Chowdhury, and A. M. Mobarak (2014): "Underinvestment in a Profitable Technology: The Case of Seasonal Migration in Bangladesh," Econometrica, 82, 1671-1748.

Cai, H., Y. Chen, H. FAng, And L.-A. Zhou (2015): "The effect of microinsurance on economic activities: evidence from a randomized field experiment," Review of Economics and Statistics, 97, 287-300.

Cardenas, J. C. and J. Carpenter (2008): "Behavioural development economics: Lessons from field labs in the developing world," Journal of Development Studies, 44, 311-338.

Carter, M. R., R. LaAjaj, And D. YAng (2014): "Subsidies and the Persistence of Technology Adoption: Field Experimental Evidence from Mozambique," Working Paper.

Chassang, S., G. Padro i Miquel, and E. Snowberg (2012): "Selective trials: A principalagent approach to randomized controlled experiments," American Economic Review, 102, 12791309.

Cohen, J. And P. Dupas (2010): "Free distribution or cost-sharing? Evidence from a randomized malaria prevention experiment," Quarterly Journal of Economics, 125, 1-45.

Cohen, J., P. Dupas, And S. Schaner (2015): "Price Subsidies, Diagnostic Tests, and Targeting of Malaria Treatment: Evidence from a Randomized Controlled Trial," The American Economic Review, 105, 609-645.

Cole, S., X. Giné, And J. Vickery (2013): "How Does Risk Management Influence Production 
Decisions? Evidence from a Field Experiment," Working Paper.

Conley, T. G. And C. R. UdRy (2010): "Learning about a new technology: Pineapple in Ghana," The American Economic Review, 35-69.

Conning, J. And C. UdRY (2007): "Rural Financial Markets in Developing Countries," in Handbook of Agricultural Economics, Elsevier, vol. Volume 3, 2857-2908.

Dercon, S. (2002): "Income risk, coping strategies, and safety nets," The World Bank Research Observer, 17, 141-166.

Dixit, A. AND R. Pindyck (1994): Investment under uncertainty, Princeton University Press.

DupAs, P. (2014): "Short-Run Subsidies and Long-Run Adoption of New Health Products: Evidence From a Field Experiment," Econometrica, 82, 197-228.

Einav, L., A. Finkelstein, S. P. Ryan, P. Schrimpf, and M. R. Cullen (2013): "Selection on Moral Hazard in Health Insurance," American Economic Review, 103, 178-219.

FAfChamps, M. (1993): "Sequential labor decisions under uncertainty: An estimable household model of West-African farmers," Econometrica, 1173-1197.

Fink, G., B. K. JACK, AND F. MASIYE (2014): "Seasonal liquidity constraints and agricultural productivity: Evidence from Zambia," Working Paper.

Fink, G. AND F. MAsiYe (2012): "Assessing the impact of scaling-up bednet coverage through agricultural loan programmes: evidence from a cluster randomised controlled trial in Katete, Zambia," Transactions of the Royal Society of Tropical Medicine and Hygiene, 106, 660-667.

Fischer, G., D. Karlan, M. McConnell, and P. Raffler (2014): "To Charge or Not to Charge: Evidence from a Health Products Experiment in Uganda," Working Paper.

Foster, A. D. And M. R. Rosenzweig (1995): "Learning by doing and learning from others: Human capital and technical change in agriculture," Journal of Political Economy, 1176-1209.

Gertler, P. And J. Gruber (2002): "Insuring consumption against illness," American Economic Review, 92, 51-70.

Giné, X. And D. YAng (2009): "Insurance, credit, and technology adoption: Field experimental evidence from Malawi," Journal of Development Economics, 89, 1-11.

Hanna, R., S. Mullainathan, And J. Schwartzstein (2014): "Learning through noticing: Theory and evidence from a field experiment," The Quarterly Journal of Economics, 129, 13111353.

Hassett, K. A. And G. E. Metcalf (1993): "Energy conservation investment: Do consumers discount the future correctly?" Energy Policy, 21, 710-716.

HeCkman, J. J. And S. NAVARRo (2005): "Empirical estimates of option values of education and information sets in a dynamic sequential choice model," Working paper.

- (2007): "Dynamic discrete choice and dynamic treatment effects," Journal of Econometrics, $136,341-396$.

Heckman, J. J., D. Schmierer, And S. Urzua (2010): "Testing the correlated random coefficient model," Journal of Econometrics, 158, 177-203.

JACK, B. K. (2013): "Private information and the allocation of land use subsidies in Malawi," American Economic Journal: Applied Economics, 5, 113-35.

Karlan, D., R. Osei, I. Osei-Akoto, and C. Udry (2014): "Agricultural Decisions after Relaxing Credit and Risk Constraints," The Quarterly Journal of Economics, 129, 597-652.

KARLAN, D. AND J. ZINMAN (2009): "Observing unobservables: Identifying information asymmetries with a consumer credit field experiment," Econometrica, 77, 1993-2008.

Magnan, N., T. J. Lybbert, R. Mrabet, and A. Fadlaoui (2011): "The quasi-option value 
of delayed input use under catastrophic drought risk: the case of no-till in Morocco," American Journal of Agricultural Economics, 93, 498-504.

Mahajan, A. AND A. TAROZZI (2011): "Time inconsistency, expectations and technology adoption: The case of insecticide treated nets," Working Paper.

Oster, E. And R. Thornton (2012): "Determinants of technology adoption: Peer effects in menstrual cup take-up," Journal of the European Economic Association, 10, 1263-1293.

PINDYCK, R. (1993): "Investments of uncertain cost," Journal of Financial Economics, 34, 53-76.

Saka, A., W. Bunderson, O. Itimu, H. Phombeya, and Y. Mbekeani (1994): "The effects of Acacia albida on soils and maize grain yields under smallholder farm conditions in Malawi," Forest Ecology and Management, 64, 217-230.

SChATZKi, T. (2003): "Options, uncertainty and sunk costs: An empirical analysis of land use change," Journal of Environmental Economics and Management, 46, 86-105.

StANGe, K. M. (2012): "An empirical investigation of the option value of college enrollment," American Economic Journal: Applied Economics, 4, 49-84.

Stavins, R. N. And A. B. Jaffe (1990): "Unintended impacts of public investments on private decisions: the depletion of forested wetlands," The American Economic Review, 337-352.

Suri, T. (2011): "Selection and comparative advantage in technology adoption," Econometrica, 79, 159-209.

Train, K. E. (2009): Discrete choice methods with simulation, Cambridge University Press. 


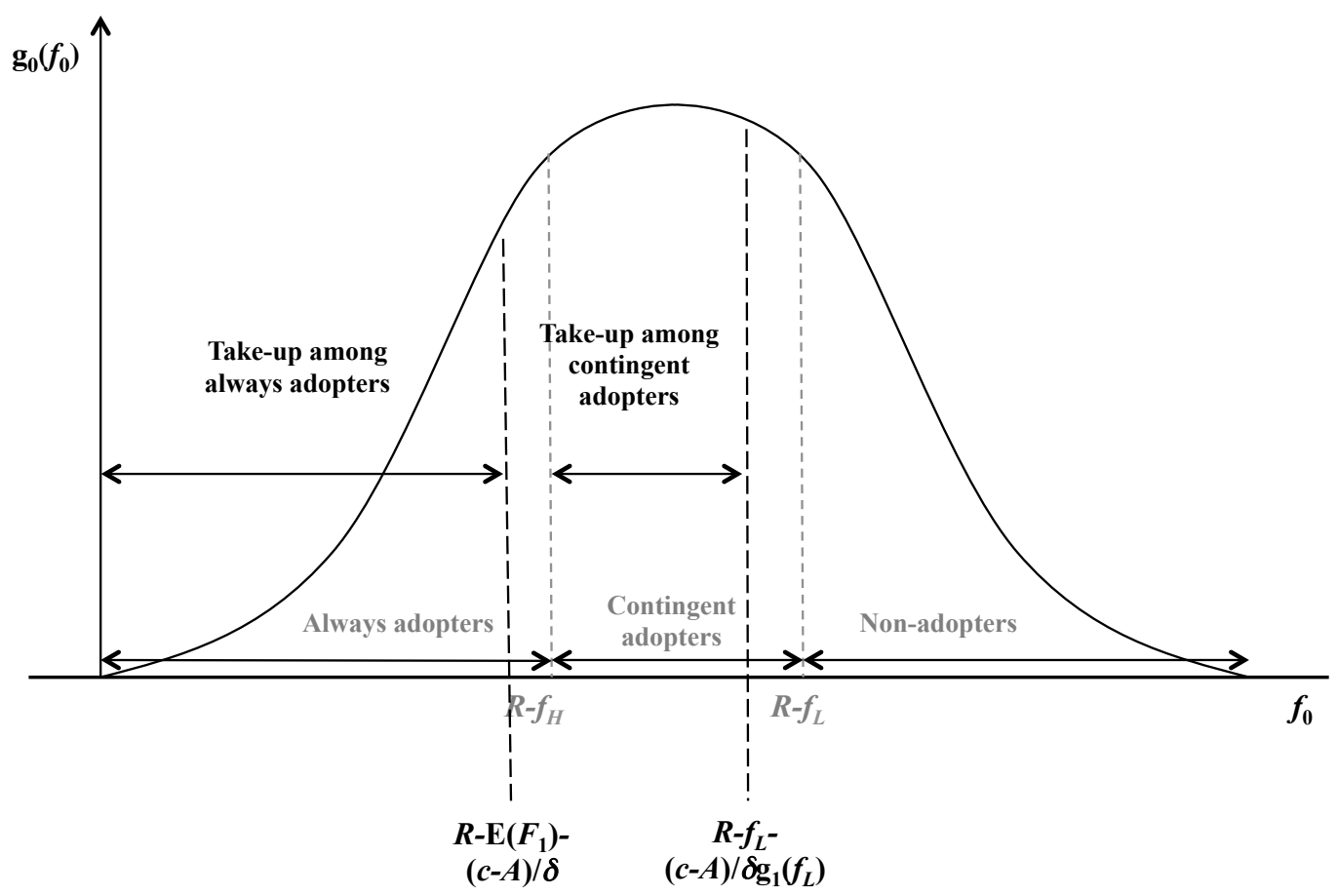

Figure 1: Take-up and follow-through thresholds as a function of agent type

Notes: The figure shows the shares of always adopters, contingent adopters and non-adopters over a symbolic probability density function of $F_{i}$. The grey thresholds $\left(R-F_{H}\right.$ and $\left.R-F_{L}\right)$ correspond to the follow-through thresholds, while the black thresholds correspond to the take-up thresholds. 


\begin{tabular}{|ccc|}
\hline Timing & Treatment & Randomization \\
\hline & $\begin{array}{c}\text { Take-up subsidy } \\
\mathrm{A}=0,4000,8000,12000 \\
\text { Time 0 }\end{array}$ & Group level \\
& $\begin{array}{c}\text { Follow-through threshold reward announced } \\
\mathrm{R}=(0(1000) \text { 150000) }\end{array}$ & Individual level \\
\hline $\begin{array}{c}\text { Time 1 } \\
(1 \text { year later })\end{array}$ & $\begin{array}{c}\text { Follow-through threshold reward } \\
\text { administered }\end{array}$ & Individual level \\
\hline
\end{tabular}

Figure 2: Experimental design

Notes: Treatments are administered at two points in time: time 0 (November 2011) and time 1 (November 2012). The take-up subsidy is applied to the bundle of 50 trees that the farmer can choose to adopt or not. The follow-through threshold reward pays out conditional on the survival of 35 or more of those trees one year later. The take-up subsidy is varied at the farmer group level; the follow-through threshold reward is varied at the individual level. See text for a description of implementation. 

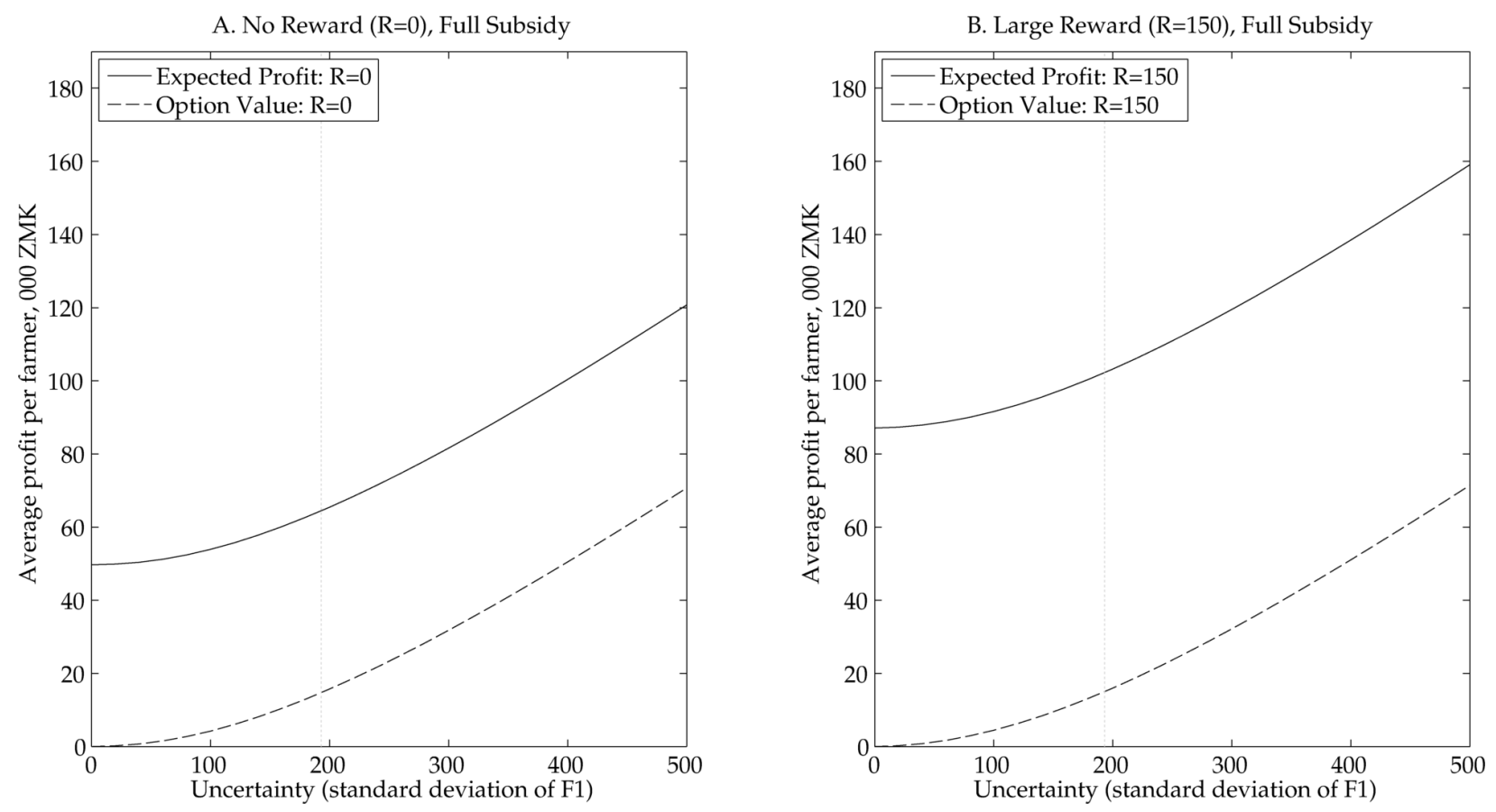

Figure 3: Farmer expected profit as a function of uncertainty

Notes: This figure shows a counterfactual simulation of farmers' mean expected profit where we vary the level of uncertainty (the standard deviation of $F_{1}$ ). For the simulations, we use the estimated parameters from Panel B of 3 , except for $\sigma_{F_{1}}$, which we vary along the horizontal axis. The mean per-farmer profit is shown in a solid black line for low (Panel A, $R=0$ ) and high (Panel B, $R=150$ ) reward values. Profits, the subsidy $(A)$ and the reward $(R)$ are expressed in thousand ZMK. The dashed lines show the mean option value for the two different reward levels. We define the option value as the difference between expected profits under the possibility of choosing the number of trees to cultivate after $F_{1}$ is realized and under the static contract (where the choice on the number of trees to cultivate has to be made ex-ante). 
A. Take-up, $\mathrm{R}=0$

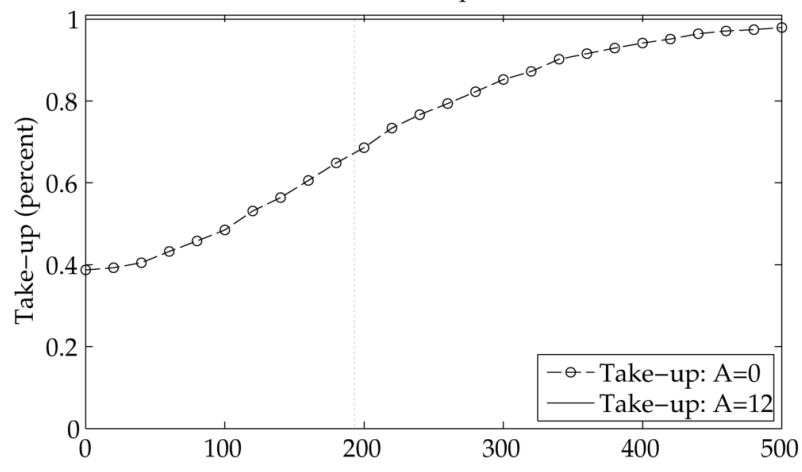

C. $35+$ trees, $R=0$

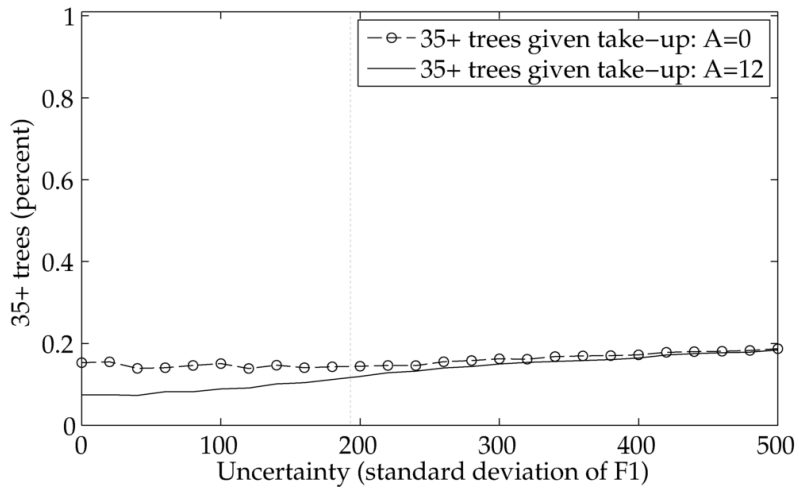

B. Take-up, $\mathrm{R}=150$

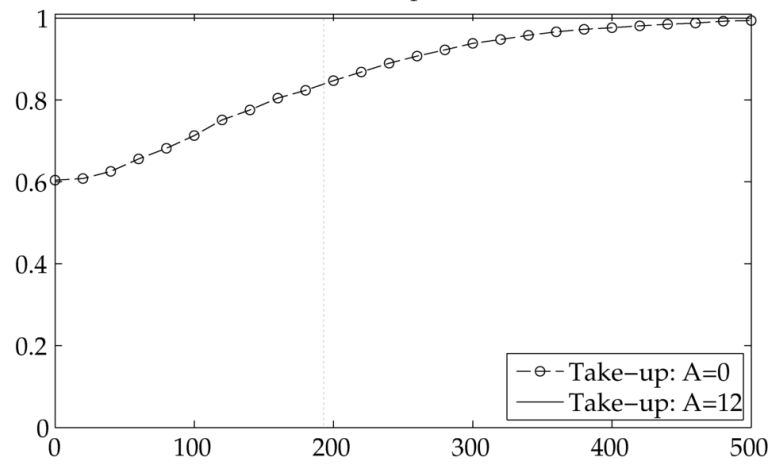

D. $35+$ trees, $R=150$

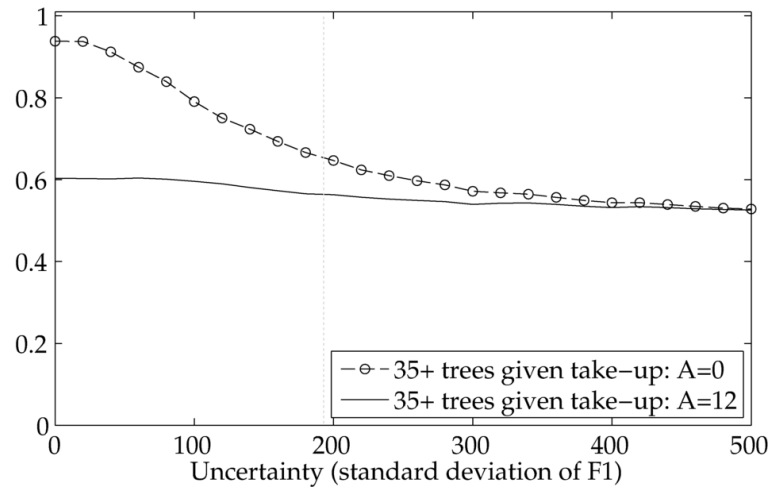

Figure 4: Take-up and threshold outcomes as a function of uncertainty

Notes: This figure shows a counterfactual simulation of farmers' average take-up and 35-tree reward threshold outcome as we vary the level of uncertainty (the standard deviation of $F_{1}$ ). For the simulations, we use the estimated parameters from Panel B of Table 3, except for $\sigma_{F_{1}}$, which we vary along the horizontal axis. Take-up and threshold (trees $\geq$ 35) outcomes are shown for different combinations of the reward value and take-up subsidy, both of which are shown in thousand ZMK. 

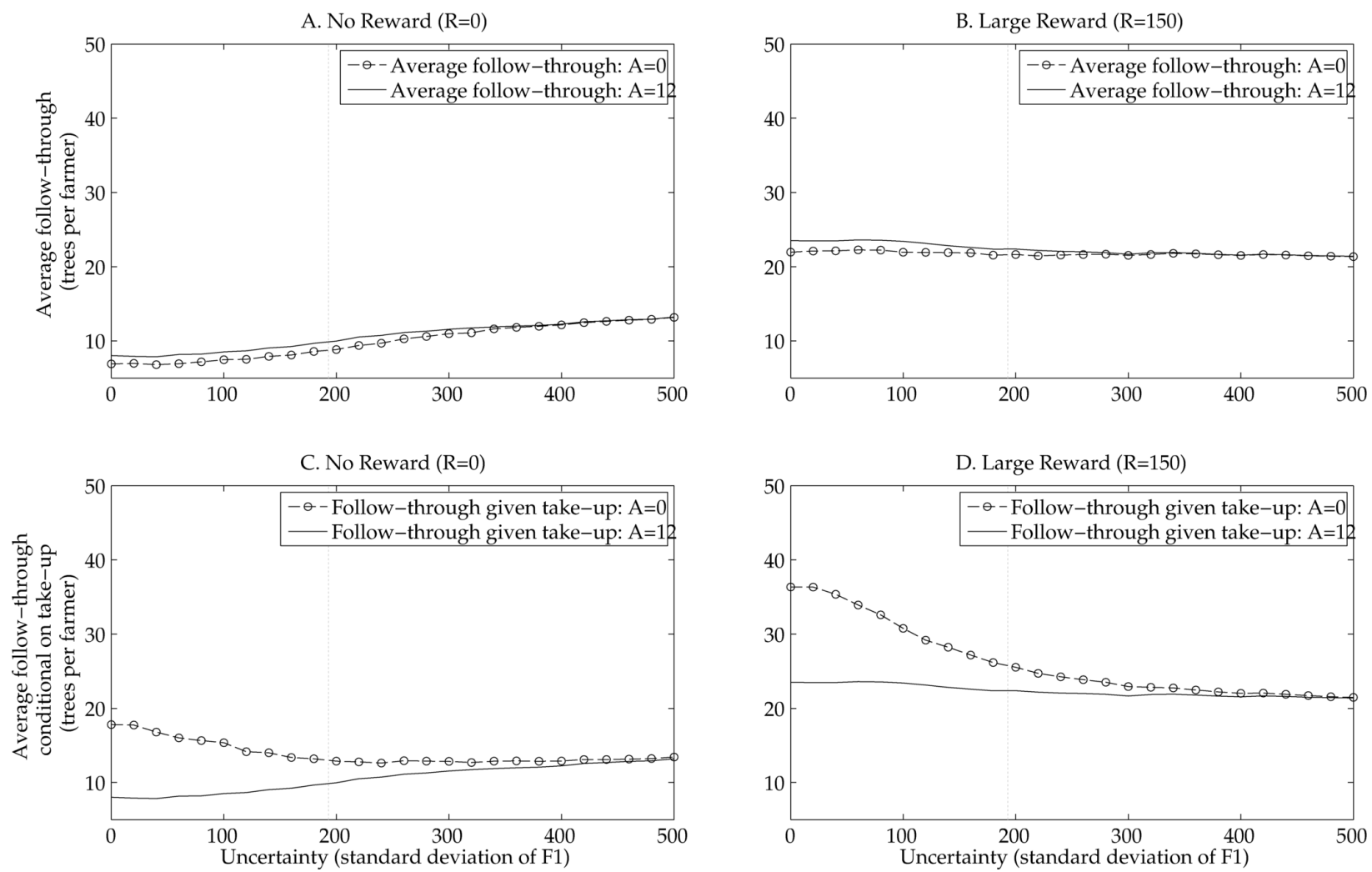

Figure 5: Tree survival as a function of uncertainty

Notes: This figure shows a counterfactual simulation of farmers' mean number of surviving trees as we vary the level of uncertainty (the standard deviation of $F_{1}$ ). For the simulations, we use the estimated parameters from Panel B of Table 3, except for $\sigma_{F_{1}}$, which we vary along the horizontal axis. The mean number of surviving trees is shown for different combinations of the external threshold reward and the subsidy for take-up, both of which are shown in thousand ZMK. The top panels show per-farmer tree survival for all farmers (those who didn't take up have zero trees); the bottom panels show tree survival conditional on take-up. 
Table 1: Summary statistics

\begin{tabular}{|c|c|c|c|c|}
\hline & $\begin{array}{c}\text { (1) } \\
\text { Take-up }\end{array}$ & $\begin{array}{c}\text { (2) } \\
\text { 35-tree } \\
\text { threshold } \\
\end{array}$ & $\begin{array}{c}(3) \\
\# \text { trees | } \\
\# \text { trees }>0\end{array}$ & $\begin{array}{c}\text { (4) } \\
\text { Zero trees }\end{array}$ \\
\hline & \multicolumn{4}{|c|}{ Panel A: full sample } \\
\hline mean & 0.83 & 0.25 & 27.42 & 0.36 \\
\hline \multirow[t]{2}{*}{ sd } & 0.38 & 0.44 & 14.31 & 0.48 \\
\hline & \multicolumn{4}{|c|}{ Panel B: by take up subsidy treatment } \\
\hline \multicolumn{5}{|l|}{$A=0$} \\
\hline mean & 0.71 & 0.26 & 27.60 & 0.37 \\
\hline sd & 0.46 & 0.44 & 14.31 & 0.48 \\
\hline \multicolumn{5}{|c|}{$A=4000$} \\
\hline mean & 0.76 & 0.29 & 28.86 & 0.36 \\
\hline sd & 0.43 & 0.45 & 13.67 & 0.48 \\
\hline \multicolumn{5}{|c|}{$A=8000$} \\
\hline mean & 0.86 & 0.27 & 29.30 & 0.38 \\
\hline sd & 0.35 & 0.44 & 14.19 & 0.49 \\
\hline \multicolumn{5}{|c|}{$A=12000$} \\
\hline mean & 0.97 & 0.22 & 24.93 & 0.33 \\
\hline \multirow[t]{2}{*}{ sd } & 0.17 & 0.41 & 14.52 & 0.47 \\
\hline & \multicolumn{4}{|c|}{ Panel C: by reward treatment } \\
\hline \multicolumn{5}{|l|}{$\mathrm{R}=0$} \\
\hline mean & 0.90 & 0.13 & 22.00 & 0.49 \\
\hline sd & 0.31 & 0.34 & 14.70 & 0.50 \\
\hline \multicolumn{5}{|c|}{$\mathrm{R}=(0,70000]$} \\
\hline mean & 0.90 & 0.21 & 25.45 & 0.40 \\
\hline $\mathrm{sd}$ & 0.30 & 0.41 & 14.62 & 0.49 \\
\hline \multicolumn{5}{|c|}{$\mathrm{R}=(70000,150000]$} \\
\hline mean & 0.93 & 0.32 & 29.53 & 0.30 \\
\hline $\mathrm{sd}$ & 0.25 & 0.47 & 13.67 & 0.46 \\
\hline
\end{tabular}

Notes: Means and standard deviations of take-up (column 1) and followthrough (columns 2-4) outcomes, by experimental treatment. Column 1 includes all farmers $(\mathrm{N}=1314)$. Columns 2-4 are conditional on take-up $(\mathrm{N}=1092)$. Column 2 reports the number of farmers who reached the performance reward threshold. 
Table 2: Farmer investments

\begin{tabular}{|c|c|c|c|c|}
\hline & $\begin{array}{c}(1) \\
\text { Weeding } \\
\end{array}$ & $\begin{array}{c}(2) \\
\text { Fire breaks } \\
\end{array}$ & $\begin{array}{c}(3) \\
\text { Watering }\end{array}$ & $\begin{array}{c}\text { (4) } \\
\text { Burning }\end{array}$ \\
\hline & \multicolumn{4}{|c|}{ Panel A: Outcome recorded during field visit } \\
\hline \multirow[t]{2}{*}{ Reward } & $0.0007 *$ & 0.0006 & $0.0008^{* *}$ & -0.0002 \\
\hline & $(0.0004)$ & $(0.0004)$ & $(0.0004)$ & $(0.0004)$ \\
\hline \multirow[t]{2}{*}{ Take-up subsidy } & -0.0062 & 0.0071 & 0.0007 & -0.0006 \\
\hline & $(0.0055)$ & $(0.0059)$ & $(0.0050)$ & $(0.0055)$ \\
\hline Reward p-value & 0.059 & 0.129 & 0.041 & 0.677 \\
\hline Mean & 0.54 & 0.36 & 0.26 & 0.40 \\
\hline \multirow[t]{2}{*}{ Observations } & 719 & 719 & 719 & 719 \\
\hline & \multicolumn{4}{|c|}{ Panel B: All contracted farmers } \\
\hline \multirow[t]{2}{*}{ Reward } & $0.0012^{* * *}$ & $0.0009 * * *$ & $0.0009 * * *$ & $0.0005^{*}$ \\
\hline & $(0.0003)$ & $(0.0003)$ & $(0.0003)$ & $(0.0003)$ \\
\hline \multirow[t]{2}{*}{ Take-up subsidy } & -0.0025 & 0.0057 & 0.0009 & 0.0014 \\
\hline & $(0.0045)$ & $(0.0040)$ & $(0.0035)$ & $(0.0041)$ \\
\hline Reward p-value & 0.000 & 0.002 & 0.002 & 0.098 \\
\hline Dep. Var. Mean & 0.36 & 0.24 & 0.17 & 0.27 \\
\hline Observations & 1,092 & 1092 & 1092 & 1092 \\
\hline
\end{tabular}

Notes: OLS regressions of observed indicators of farmer effort, measured during tree survival monitoring, on treatment variables. The reward and take-up subsidy are both measured in thousand ZMK. Regressions control for an effort monitoring indicator and cluster standard errors at the farmer group level. 
Table 3: Structural parameter estimates

\begin{tabular}{|c|c|c|c|c|c|c|c|c|}
\hline \multicolumn{3}{|c|}{ Parameters in $\mathrm{T}$} & \multicolumn{6}{|c|}{ Parameters in F } \\
\hline$\mu_{T}$ & $\sigma_{T}$ & $\varrho$ & $\mu_{F}$ & $\sigma_{F 0}$ & $\sigma_{F I}$ & $\alpha_{s}$ & $\alpha_{m}$ & $\mu_{F s}$ \\
\hline \multicolumn{9}{|c|}{ Panel A. No Mean Shift } \\
\hline 3.539 & 1.401 & 0.818 & 107.58 & 307.87 & 211.42 & -91.79 & -238.40 & - \\
\hline$(0.057)$ & $(0.066)$ & $(0.066)$ & $(11.822)$ & $(93.278)$ & $(49.953)$ & $(16.222)$ & $(73.887)$ & - \\
\hline \multicolumn{9}{|c|}{ Panel B. Allowing for Mean Shift } \\
\hline 3.579 & 1.392 & 0.835 & 74.48 & 290.06 & 193.05 & -54.42 & -229.53 & 53.29 \\
\hline$(0.071)$ & $(0.075)$ & $(0.073)$ & $(15.47)$ & $(84.622)$ & $(45.427)$ & $(20.47)$ & $(74.444)$ & $(26.761)$ \\
\hline
\end{tabular}

Notes: Parameters fitted by simulated maximum likelihood using 1500 draws of the random vector $\left(F_{0 i}, F_{i j}, T_{i}\right)$, with smoothing (lambda is 0.5) and tolerance (1e-15). The baseline model (Panel A) restricts the mean of $F_{i}$ to be the same in both time periods. The mean shift model (Panel B) allows the mean of $F_{i}$ to differ between the two periods, and the parameter F_shift to capture this difference. The log-likelihood value for the baseline model is 11142.064, while it is 11138.996 for the mean shift model. 
Table 4: Comparison of structural and reduced form estimates

\begin{tabular}{|c|c|c|c|c|c|c|c|c|c|}
\hline & $\begin{array}{c}\text { (1) } \\
\text { Take-up }\end{array}$ & $\begin{array}{c}(2) \\
\text { 35-tree } \\
\text { threshold }\end{array}$ & $\begin{array}{c}(3) \\
\# \text { trees | } \\
\# \text { trees }>0\end{array}$ & $\begin{array}{c}(4) \\
\text { 1.(zero } \\
\text { trees) }\end{array}$ & & $\begin{array}{c}\text { (5) } \\
\text { Take-up }\end{array}$ & $\begin{array}{c}\text { (6) } \\
\text { 35-tree } \\
\text { threshold }\end{array}$ & $\begin{array}{c}(7) \\
\# \text { trees | } \\
\# \text { trees }>0\end{array}$ & $\begin{array}{c}(8) \\
\text { 1.(zero } \\
\text { trees) }\end{array}$ \\
\hline \multirow[b]{2}{*}{ Take-up subsidy } & \multicolumn{9}{|c|}{ Panel A. Observed Data } \\
\hline & $\begin{array}{c}0.022^{* * *} \\
(0.005)\end{array}$ & $\begin{array}{l}-0.004 \\
(0.004)\end{array}$ & $\begin{array}{l}-0.229 \\
(0.200)\end{array}$ & $\begin{array}{l}-0.003 \\
(0.005)\end{array}$ & Reward & $\begin{array}{c}0.001 * \\
(0.000)\end{array}$ & $\begin{array}{c}0.001 * * * \\
(0.000)\end{array}$ & $\begin{array}{c}0.044 * * * \\
(0.013)\end{array}$ & $\begin{array}{c}-0.001 * * * \\
(0.000)\end{array}$ \\
\hline Observations & 1,314 & 1,092 & 701 & 1,092 & & 624 & 1,092 & 701 & 1,092 \\
\hline R-squared & 0.071 & 0.002 & 0.005 & 0.001 & & 0.006 & 0.018 & 0.022 & 0.013 \\
\hline & \multicolumn{9}{|c|}{ Panel B. No Mean Shift } \\
\hline Take-up subsidy & $\begin{array}{c}0.021 * * * \\
(0.002)\end{array}$ & $\begin{array}{l}-0.003 \\
(0.003)\end{array}$ & $\begin{array}{c}0.061 \\
(0.130)\end{array}$ & $\begin{array}{c}0.010^{* * *} \\
(0.003)\end{array}$ & Reward & $\begin{array}{c}0.001 * \\
(0.000)\end{array}$ & $\begin{array}{c}0.003^{* * *} \\
(0.000)\end{array}$ & $\begin{array}{c}0.091 * * * \\
(0.012)\end{array}$ & $\begin{array}{c}-0.001 * * * \\
(0.000)\end{array}$ \\
\hline Observations & 1,314 & 1,104 & 625 & 1,104 & & 624 & 1,104 & 625 & 1,104 \\
\hline \multirow[t]{2}{*}{ R-squared } & 0.069 & 0.001 & 0.000 & 0.009 & & 0.005 & 0.105 & 0.082 & 0.011 \\
\hline & \multicolumn{9}{|c|}{ Panel C. Allowing for Mean Shift } \\
\hline Take-up subsidy & $\begin{array}{c}0.020 * * * \\
(0.002)\end{array}$ & $\begin{array}{l}-0.004 \\
(0.003)\end{array}$ & $\begin{array}{c}0.022 \\
(0.131)\end{array}$ & $\begin{array}{c}0.009 * * * \\
(0.003)\end{array}$ & Reward & $\begin{array}{c}0.001 * \\
(0.000)\end{array}$ & $\begin{array}{c}0.003^{* * *} \\
(0.000)\end{array}$ & $\begin{array}{c}0.094 * * * \\
(0.012)\end{array}$ & $\begin{array}{c}-0.001 \text { *** } \\
(0.000)\end{array}$ \\
\hline Observations & 1,314 & 1,112 & 603 & 1,112 & & 624 & 1,112 & 603 & 1,112 \\
\hline R-squared & 0.066 & 0.001 & 0.000 & 0.007 & & 0.005 & 0.104 & 0.088 & 0.013 \\
\hline
\end{tabular}

Notes: This table shows coefficients from regressions of each of four indicator variables (take up, threshold of 35 trees reached, tree survival larger than zero, and no tree survival) on each of our randomized treatments (take-up subsidy and threshold reward, measured in thousand ZMK). Panel A shows these regression outcomes for the true data. Panel B and C show the fit of the strcutural model by simulating all four outocomes using the model estimates and examining the how much the linear relationships between outcomes and treatments resemble those in Panel A. Panel B uses baseline model estimates (Panel A of Table 3), while Panel C uses estimates from the mean shift model (Panel B of Table 3). 